\title{
Extreme Ice Crystal Events Linked to Biomass and Fossil Fuel Combustion
}

Graciela B. Raga ${ }^{1}$, Darrel Baumgardner ${ }^{2}$, Blanca Rios ${ }^{1}$, Yanet Díaz-Esteban ${ }^{1}$, Alejandro Jaramillo $^{1}$, Martin Gallagher ${ }^{3}$, Bastien Sauvage ${ }^{5}$, Pawel Wolff ${ }^{5}$ and Gary Lloyd $d^{3,4}$

5

${ }^{1}$ Centro de Ciencias de la Atmósfera, Universidad Nacional Autónoma de México, Mexico City, Mexico

${ }^{2}$ Droplet Measurement Technologies, LLC, Longmont, CO, USA

${ }^{3}$ Centre for Atmospheric Science, University of Manchester, Manchester M13 9PL, UK

${ }^{4}$ National Centre for Atmospheric Science (NCAS), University of Manchester, Manchester M13 9PL, UK

10 Laboratoire d'aérologie (LA), CNRS UMR-5560 et Observatoire Midi-Pyrénées, Université de Toulouse, France

Correspondence to: Darrel Baumgardner (Darrel.baumgardner@gmail.com)

Abstract. Eight years of upper tropospheric (UT) ice crystal measurements with the Backscatter Cloud Probe (BCP), operated as part of the In-Service Aircraft for a Global Observing System (IAGOS), have been analyzed to assess the frequency and characteristics of extreme ice crystal events (EIE), defined in this study as encounters with clouds that have number concentrations exceeding $5000 \mathrm{~L}^{-1}$. A total of 6490 events, in clouds of horizontal extent $\geq 2.5 \mathrm{~km}$, were identified during the period from December 2011 to March 2020 in the global band between $30^{\circ} \mathrm{S}$ and $30^{\circ} \mathrm{N}$. Evaluation of in situ measurements of carbon monoxide in these UT clouds, combined with back-trajectories and carbon monoxide emission inventories, allow the identification of regional anthropogenic sources. An evaluation of low- and upper-level kinematic variables from the Modern-Era Retrospective analysis for Research and Applications, Version 2 (MERRA-2), combined with spatial distribution of aerosol optical depth and regions of biomass burning, reveal the physical mechanism by which the particles are lofted to flight levels in regions of deep convection. The maps of lightning frequency derived from the World Wide Lightning Location Network (WWLLN) contribute additional evidence of the role of deep convection lofting ice forming aerosols to the UT. The MERRA-2 analysis shows clear spatial correlations that link dust, black carbon (BC), organic carbon (OC) and sulfate particles with regions of EIE. Given the composition of the source aerosols and the nature of their transport to the UT, the ice clouds are likely of liquid origin whereby droplets formed on these particles are lofted and freeze heterogeneously as have been reported in previous studies. The results from this study have important ramifications related to climate change, satellite measurement validation, weather forecasting and aircraft operations.

Keywords: Ice crystal concentrations, IAGOS, biomass burning, urban pollution, ice nucleating particles, immersion freezing

\subsection{Introduction}

The studies by Krämer et al $(2016,2020)$ provide a comprehensive description of the origins and microphysical properties of cirrus clouds based on 150 flights with nine research aircraft that accumulated 168 hours of cloud measurements during various field campaigns in the mid-latitudes and tropics over a period of 19 years (1999-2017). 

$\left(\mathrm{R}_{\mathrm{ice}}\right)$ as a function of ambient temperature, the in situ measurements were compared to 10 years of cirrus ice number concentrations derived from satellite measurements. This extensive data set serves to underscore the importance of aircraft measurements, not only to document cirrus properties, but also to provide the detailed information about those characteristics that cannot be extracted from the lower spatial resolution satellite data. For example, in the comparisons discussed by Krämer et al (2020), the $\mathrm{N}_{\text {ice }}$ derived from satellites was found to be, on average, a factor of two higher than in situ measurements, a significant difference that had also been noted by Gasparini et al. (2018). Furthermore, in situ measurements have provided the information needed to refine parametrizations and improve the representation of cirrus clouds and their microphysical and optical properties more accurately in climate models (Kärcher, 2018; Kärcher et al., 2010).

The European Research Infrastructure program IAGOS (In-service Aircraft for a Global Observing System) was developed with the primary objective of building a database of global measurements, over an extended period of time, as a source of information that would be truly representative across all temporal and spatial scales (Petzold et al., 2015). Although the instrumentation on the IAGOS aircraft fleet is not nearly as comprehensive as that found on the typical cloud research aircraft (Petzold et al., 2015), Beswick et al. (2015) showed that the cirrus cloud microphysical statistics, acquired with the cloud probes installed on the IAGOS aircraft, were in good agreement with those that were summarized in published studies compiled from aircraft-based research campaigns. This leads us to conclude that data taken during the IAGOS flights should be considered as an integral and complementary component of the global data set of cirrus measurements, as summarized by Krämer et al $(2016,2020)$.

60

The current study expands the analysis of the 3-year dataset presented by Beswick et al. (2015) to an evaluation through March 2020 and complements the results recently reported by Lloyd et al. (2021), significantly increasing the number of clouds sampled. Beswick et al. (2015) identified frequent events in which $\mathrm{N}_{\text {ice }}$ exceeded $10000 \mathrm{~L}^{-1}$, a concentration that is more than 300 times larger than the median values and 30 times larger than the $90^{\text {th }}$ percentile reported by Krämer et al. (2020) for $\mathrm{N}_{\text {ice }}$ measured in situ and derived from CALIPSO and CloudSat measurements (Sourdeval et al., 2018).

The analysis conducted for the present study, over the larger data set, shows that concentrations of $>5000 \mathrm{~L}^{-1}$ fall in the $85^{\text {th }}$ percentile of all upper tropospheric (UT) ice clouds measured, a value more than 10 times the $90^{\text {th }}$ percentile reported by Krämer et al. (2020) of $300 \mathrm{~L}^{-1}$. Note that while the previously mentioned in situ studies refer to clouds in the UT as cirrus, we wish to clarify that a large percentage of the clouds that we report in this study are measured in the upper regions of cumulonimbus and in their anvils. Hence, from this point onward we will refer to all the clouds measured as "ice clouds" and to all cloud encounters when ice crystal concentrations exceed $5000 \mathrm{~L}^{-1}$ as Extreme Ice Events (EIE). This latter definition of an EIE is created with reference to the median and $90^{\text {th }}$ percentile values reported from previous in situ and satellite studies. The term EIE should not be confused with or equated to the term Ice Crystal 
Icing (ICI), a definition used by the community of scientists who study how ice crystals impact aircraft performance. ICI is usually associated with ice water content and not with ice number concentration, although the two variables are obviously linked. The present study focuses on understanding the processes that result in high $\mathrm{N}_{\text {ice }}$ and on the identification of the sources of the precursor aerosols that form these crystals.

Ice crystals form on aerosol particles via a number of processes (Kanji et al., 2017). The two most frequent pathways are through immersion or contact freezing: 1) water droplets form on cloud condensation nuclei (CCN) and, when advected to regions of low temperatures, freeze due to the presence of ice nucleating particles (INP) embedded in the water droplets or 2) by surface contact with INP (Krämer et al., 2016).

Beswick et al. (2015) suggested that the high ice crystal concentrations detected in the maritime-continental, tropical region over Malaysia were possibly linked to biomass burning. Observational and theoretical studies have shown how gaseous and particulate emissions from not only biomass burning (BB), but also from urban pollution (UP), can reach aircraft cruising altitude where ice crystal clouds are found (Osman et al., 2016; Ditas et al., 2018; Hirsch and Koren,

90 2021). Some fraction of particles emitted from biomass and fossil fuel burning will act as CCN or INP especially as they age while lofted to the UT (Brooks et al. 2014; Gorbunov et al. 2001; Grawe et al. 2016; Popovicheva et al. 2008; Umo et al. 2015; Knopf et al. 2018; Jahl et al., 2021).

Ding et al. (2015) used spaceborne Measurements of Pollution in the Troposphere (MOPITT) data, in combination 95 with aircraft measurements from the Measurement of Ozone and Water Vapor by Airbus In-Service Aircraft (MOZAIC) program to document the presence of anomalously high carbon monoxide (CO) in the upper troposphere over East Asia. They used back-trajectory analysis to link anthropogenic sources over the Sichuan Basin and the North China Plain and from forest fires over Indochina. The CO was transported to such altitudes through strong frontal lifting, embedded deep convection and by orographic forcing.

Osman et al. (2016) developed a climatology of CO using trajectory mapping of data from MOZAIC and IAGOS that linked biomass burning in central and southern Africa and anthropogenic emissions in eastern China to upper tropospheric CO anomalies. Similar results are reported by Sheel et al (2016) over central India.

105 Yamasoe et al. (2015) employed the MOZAIC/IAGOS database, complemented with model simulations, to link the contributions of CO in the Upper Troposphere and Lower Stratosphere (UTLS) to local, Central and North American, Caribbean and African anthropogenic and BB emissions. Ditas et al. (2018) encountered frequent BB plumes in the UTLS over the Atlantic Ocean. The refractory black carbon (rBC) mass concentration in these plumes was measured by the Single Particle Soot Photometer (SP2; Baumgardner et al. 2004). The average rBC concentrations in these

110 plumes were more than 20 times higher than background values. Nearly all of the rBC particles sampled in the UTLS were covered with a thick coating, an indicator of aging that increases the $\mathrm{CCN}$ activity of BC. 
The importance of the Asian Summer Monsoon (ASM) for lofting anthropogenic pollution and forming the Asian Tropopause Aerosol Layer (ATAL) is discussed by Vernier et al. (2015). Aircraft measurements identified particles composed of carbonaceous and sulfate materials and CALIPSO observations indicated that deep convection associated with the ASM transports surface pollution particles to the ATAL.

Figure 1 shows the locations of EIE observed worldwide between December 2011 and March 2020 along with megacities, i.e., those urban areas with populations larger than 10 million. These high ice concentration events are encountered over almost all the continents where the IAGOS aircraft fly; however, the majority of the EIE are found between $\pm 30^{\circ}$ latitude where the larger number of megacities are located. The EIE are clustered along the flight routes from Europe to South America and to Africa, but the majority of events are found in the large cluster centered around Taiwan and radiating towards India, Japan, Indonesia and Australia/Oceania. The color-coded markers indicate the ice crystal number concentration within each EIE and, while the majority of concentrations range between 5000 and $20000 \mathrm{~L}^{-1}$ (purple markers), there are a number of regions where concentrations exceeding $50000 \mathrm{~L}^{-1}$ were detected, as indicated by green, yellow and red circles.

This study will show that high ice concentrations along commercial flight tracks are frequently found along with evidence from BB and UP emissions. The case for linking surface, anthropogenic emissions with the EIE is made in the following sections. An analysis of in situ cloud and CO measurements, coupled with back-trajectory modeling of the $\mathrm{CO}$, identifies the possible sources of ice crystal nuclei. A complementary analysis links the location of the EIE with the climatological patterns of upper-level divergence as proxy for regions of upward vertical motion, lightning, outgoing long-wave radiation (OLR), aerosol optical depth (AOD) and regional composition of aerosol particles in the UT.

The objectives of the following study are fourfold: 1) to document the frequency of EIE by geographic region within the latitude band most impacted by BB and UP emissions, 2) to evaluate the seasonal impact as related to dry and rainy periods, 3) to link the EIE to sources of INP and 4) to provide compelling evidence that particles generated at the surface are the source of the ice crystals encountered in UT clouds by commercial aircraft.

\subsection{Measurement and Analysis Methodology}

The ice crystal measurements are made with Backscatter Cloud Probes (BCP; Droplet Measurement Technologies,

145 LLC), whose detection principles are described by Beswick et al (2014). The BCP is mounted inside the aircraft and interfaces to a window plate that also holds the inlet that brings ambient air to the gas analyzers (Nédélec et al., 2003;2016). The BCP transmits a laser beam through the window and ice crystals that intersect this beam then scatter 
light. Some fraction of the backscattered light is collected through the same window and the collected photons are converted to an electrical signal that is processed and used to derive an equivalent optical diameter (EOD). The nominal size range is $5-90 \mu \mathrm{m}$ with an estimated uncertainty of $\pm 30 \%$ when deriving the EOD of ice crystals. Detected crystals are binned by size into a 10-channel frequency histogram that is transmitted to the data acquisition system every four seconds. The number concentration is calculated as the number of particles detected divided by the volume of sampled air. The BCP samples $250 \mathrm{~cm}^{3}$ every four seconds, a spatial resolution of approximately one kilometer at normal cruise altitude airspeeds of $250 \mathrm{~ms}^{-1}$ for Airbus A330/A340 IAGOS aircraft.

The ice crystal concentrations reported in this study are the maximum values from individual clouds, where clouds are identified as those encountered at an altitude $\geq 8000 \mathrm{~m}$ and that have a measured $\mathrm{N}_{\mathrm{ice}} \geq 50 \mathrm{~L}^{-1}$. This latter threshold is imposed to ensure that the number of crystals sampled are statistically representative of a cloud's parent population with an uncertainty $<30 \%$ (Beswick et al., 2015; Lloyd et al., 2020).

Carbon monoxide (CO) concentrations are measured with a Thermo Scientific Model 48 that has been modified to improve its performance, including the use of an optimized IR detector, cell pressurization, air drying and frequent zeroing (Nédélec et al.,2003). A 30-s integration time is used to obtain a minimum detection limit of 10 ppbv and thus, the $\mathrm{CO}$ samples are obtained at a horizontal resolution of about $7.5 \mathrm{~km}$ at cruise speeds.

The sampled air mass histories are evaluated using the FLEXPART Lagrangian particle dispersion model (Stohl et al., 2005) that simulates the long-range and mesoscale transport of tracers released from point, line, area or volume sources. The CO concentrations detected at cruising altitude are linked to emissions of fossil fuel combustion from urban regions and from biomass burning using the SOFT-IO tool, as described in detail by Sauvage et al. (2017a).

170 The SOFT-IO model utilizes the Emissions of Atmospheric Compounds \& Compilation of Ancillary Data (ECCAD) database that documents inventories of global emissions from UP (MACCity) and BB (GFAS).

For every IAGOS flight from 2011 to 2020 when the CO sensor was operational, the FLEXPART back trajectories were computed for each sampling point along the flight paths, estimating the location of the sampled air as far back 175 as 20 days prior to its arrival at the aircraft. The model incorporates the wind fields from the 6-hourly operational analyses and $3 \mathrm{~h}$ forecasts by the European Centre for Medium-Range Weather Forecast (ECMWF).

We are particularly interested in identifying anomalous $\mathrm{CO}$ mixing ratios within the database that would indicate plumes originating from surface UP or BB emissions. Sauvage et al. (2017a) identify these anomalies through a methodology implemented to detect pollution layers in the IAGOS database (Petetin et al., 2018; Cussac et al., 2020). One of the products that is available through the IAGOS central database is flight-by-flight netCDF files that provide the $\mathrm{CO}$ mixing ratio that has been transported from either biomass burning or urban regions and that exceeds the background (Sauvage et al., 2017a, b), i.e., the CO anomaly. For the UT the background CO mixing ratio is determined by calculating seasonal median values (over the entire IAGOS database) for 10 different regions worldwide. These 
185 background CO values are subtracted from each SOFT-IO simulated CO mixing ratio every four seconds along the flight track; the anomaly $\Delta \mathrm{CO}>0$, in units of ppbv, are indicative of the possible influence of surface emissions of UP and/or BB.

The data files with the SOFT-IO simulations are archived through the IAGOS central database (http://iagos. sedoo.fr/\#L4Place) and are part of the ancillary products (https://doi.org/10.25326/3) (Sauvage et al., 2017b, c). Each flight is archived separately and provides the mixing ratios of $\mathrm{CO}$ contributions from 14 anthropogenic and biomass emitting regions. The latter regions are those documented in the global fires data base (http://www.globalfiredata.org/data.html). Values larger than zero indicate an anomalously large mixing ratio that exceeds background while null values are recorded when differences with the background are zero or negative. The modeled $\mathrm{CO}$ values were gridded in $0.25^{\circ} \times 0.25^{\circ}$ cells for comparison with the cloud data.

The modeled CO anomalies were compared with anomalous values derived from the in situ measured CO, using a similar approach for establishing background values. For each flight, the median $\mathrm{CO}$ values were calculated at altitudes between 8 and $12 \mathrm{~km}$ and used as the background. A positive difference between the measured value and the median is designated as an anomaly. These anomalies were compared with those from the SOFT-IO simulated anomalies and the differences were generally less than $20 \%$, serving as a quality check of the model results that are used to identify the sources of these anomalies.

The current study considers only observations within the $-30^{\circ}$ to $+30^{\circ}$ latitude band and from $-50^{\circ}$ to $+180^{\circ}$ in longitude, leaving out most of the high latitude flights in the northern hemisphere. Moreover, the analysis merges the 14 SOFT-IO regions into four larger ones: 1) Australia and Oceania (AO), 2) Persia, India and SE Asia (PIA), 3) Northern Hemisphere Africa and Atlantic Ocean (NHAA), and 4) Southern Hemisphere Africa and Atlantic Ocean (SHAA). These regions were selected because they encompass the majority of the EIE encountered in this latitude band and the regions where most of the BB and UP emissions are located. The data are further discriminated into rainy and dry seasons.

Data from the Moderate Resolution Imaging Spectroradiometers (MODIS) sensors on the Aqua and Terra satellites are used. Specifically, the Thermal Anomalies Level 2 Collection 6 data products (MYD14 and MOD14, Giglio et al., 2016) that provide the location of fires and their fire radiative power (FRP) at a spatial resolution of $1 \mathrm{~km}$ at nadir.

215 The FRP (MW or MJ/s) was developed by Kaufman et al. (1998) from the $4 \mu \mathrm{m}$ and $11 \mu \mathrm{m}$ bands to determine fire intensity, which is linked to emissions. Monthly climatological maps are calculated from Aqua (nadir pass at 1:30pm LT) and Terra (nadir pass at 10:30am LT) over the period 2011-2019. Further, we use the aerosol optical depth (AOD) products from MOD04-Terra and MYD04-Aqua (Remer et al., 2009) at 550-nm wavelength and a spatial resolution of $10 \mathrm{~km}$ at nadir. 
The new generation reanalysis from the European Centre for Medium-Range Weather Forecasts (ECMWF), ERA5 (Hersbach et al., 2018) at $1^{\circ}$ horizontal resolution is used to estimate climatological values of several meteorological variables such as upper-level horizontal wind divergence and outgoing longwave radiation (OLR). and Applications, Version 2) are analyzed over the same time period as the IAGOS measurements. MERRA-2, produced by NASA's Global Modeling and Assimilation Office (GMAO), is a multi-decadal global dataset that combines hyperspectral radiance, microwave data, GPS-Radio occultation data, ozone profile observations, and several other ground and satellite-based datasets (Randles et al., 2017; Gelaro et al., 2017). The horizontal resolution is $0.625^{\circ}$ (long.) $\times 0.5^{\circ}$ (lat.). The M2I3NVAER product in 72 vertical levels is generated from the output of the Goddard Chemistry Aerosol Radiation and Transport model (GOCART), which simulates an external mixture of 15 particle types. The importance of MERRA-2 in this study is that it provides a gridded output of speciated aerosol mixing ratios (Bocquet et al., 2015; Gelaro et al., 2017), i.e., dust, organic carbon and black carbon (OC, BC) and sulfate $\left(\mathrm{SO}_{4}\right)$. The mixing ratios of the different particle types in the layers between 8 and $12 \mathrm{~km}$ were averaged (weighted) and converted to standard temperature and pressure to determine concentrations.

Lighting flash counts and locations over the period 2011 to 2018 were obtained from the World Wide Lightning Location Network (WWLLN) (Dowden et al., 2002) and were gridded to coincide with the MERRA-2 horizontal grid.

\subsection{Results}

240 The measurements were made with BCPs and CO analyzers installed on eight Airbus A330/A340 IAGOS aircraft. The data analyzed cover the period from December 2011 to March 2020, a total of 22857 flights, during which 67172 ice crystal clouds were sampled, accumulating 1483 hours in clouds.

\subsection{Cloud statistics}

The cumulative frequencies are calculated for ice crystal number concentrations grouped into each of the five regions mentioned above (Fig. 2a) and as a function of season (Fig. 2b). The distribution representing all clouds (black curve) reaches $5000 \mathrm{~L}^{-1}$ at the $85^{\text {th }}$ percentile, the concentration that we will designate as the EIE threshold (indicated by the vertical dashed lines in Fig 2). The northern and southern NHAA and SHAA regions (orange and red curves) show similar frequency distributions above the EIE threshold, with $15 \%$ of the clouds in the EIE category, those in the AO region (teal curve) have $25 \%$ of the clouds with concentrations $>5000 \mathrm{~L}^{-1}$ while the PIA regions (blue curve) had $20 \%$ of the clouds with concentrations greater than the EIE. Differences in the frequency distributions as a function of dry vs rainy seasons, independent of the regional areas, are slight (Fig. 2b), 13\% vs 18\%, respectively.

All of the ice number concentrations in the region of interest were mapped as a function of temperature similar to how Krämer et al (2020) presented their cloud climatology. Figure 3 shows the frequency of $\mathrm{N}_{\text {ice }}$ as a function of temperature with the median and $90^{\text {th }}$ percentile values drawn in yellow lines, solid and dashed, respectively. Also 
drawn on this figure are the climatological values reported by Krämer et al (2020), those from in situ observations are drawn in orange and from the satellite-derived DARDAR- $\mathrm{N}_{\text {ice }}$ (Sourdeval et al, 2018) in magenta. The range in the BCP N $\mathrm{N}_{\text {ice }}$ is somewhat smaller than Krämer et al (2020), $0.01-100 \mathrm{~cm}^{-3}$, vs $0.0001-1000$, as is the temperature, 210$245 \mathrm{~K}$ vs 185 to 245 . Nevertheless, the IAGOS data set from 2011-2020 is in very good agreement with the in situ climatology from the years 1999- 2017 that was generated from a much smaller set of measurements.

\subsection{Carbon monoxide statistics}

The CO anomalies, derived from the SOFT-IO model at cruising altitude, are separated into different categories considering the region, season and type of source (all anomalies and those associated with BB or UP emissions), as shown in Fig. 4 with statistics listed in Table 1 . The data are binned into $0.25^{\circ} \times 0.25^{\circ}$ bins $(28 \mathrm{~km} \mathrm{x} 28 \mathrm{~km})$ and the maximum BB and UP anomalies were calculated at each grid point. All of the gridded maxima are averaged to produce Fig. 4a. The average maximum CO anomalies due to BB are larger in the AO and PIA regions while those due to UP and BB are comparable in the NHAA and SHAA (Fig. 4a). These differences in averages, however, are not statistically significant because of the large standard deviations (Table 1) Similarly, although the average CO anomalies appear to be twice as large during the rainy season for the AO, PIA and SHAA, the standard deviations are also quite large (Table 1).

Figure 5 highlights the frequency with which the $\mathrm{CO}$ anomalies measured over each region are coming from source regions different than the ones in which they were measured. The frequency of $\mathrm{CO}$ anomalies due to $\mathrm{CO}$ from biomass burning sources is shown in Fig. 5a and from urban pollution in Fig. 5b. The emissions from BB and UP in the PIA region dominate the anomalies in $\mathrm{CO}$ over the $\mathrm{AO}$ and PIA (Figs. 5a, b). Over the NHAA and SHAA regions it is the $\mathrm{BB}$ emissions from the NHAA that have the largest influence on $\mathrm{CO}$ anomalies encountered over the Africa and Atlantic regions (Fig 5a). The CO anomalies from UP sources, over the NHAA and SHAA, are primarily from surface sources in these same regions (Fig. 5b).

\subsection{Combined carbon monoxide and cloud statistics}

280 The cumulative frequency distributions of $\mathrm{CO}$ anomalies, differentiated by the source of the anomalies based on the model and grouped by the EIE and non-EIE, are shown in Fig. 6. In addition, CO anomalies were estimated from the measured $\mathrm{CO}$ along the flight track, where the anomalies were calculated by subtracting the average background $\mathrm{CO}$. In Fig. 6 the horizontal black line at 50\% intersects all the curves at their median values. The median, modeled CO anomalies for EIE and non EIE are 2.5 and $3.5 \mathrm{ppb}$ for $\mathrm{CO}$ from BB, respectively (green curves). The median value

285 for $\mathrm{CO}$ from fossil fuel emissions is $10 \mathrm{ppb}$ (black curves), with no difference between anomalies encountered in EIE and non-EIE.

Compared with the modeled anomalies, the measurement-derived CO anomalies (red curves) have median values of 15 and $18 \mathrm{ppb}$, respectively for the EIE and non-EIE. Although these results suggest that the anomalies are larger in the non-EIE, the differences are not large enough to conclude that surface emissions from combustion could have a 
larger impact on the non-EIE. The frequency distributions do suggest that emissions from UP sources are potentially a larger source of nucleating particles in the ice clouds, in general.

Figure 7 shows the locations of 1) CO anomalies that are not associated with ice clouds (black dots), 2) ice clouds with no $\mathrm{CO}$ anomalies (blue dots) and 3) clouds with anomalies (yellow dots, Fig. 7a and magenta dots in Fig. 7b). Figure 7a includes all ice clouds and Fig. 7b is with EIE only. With the exception of several flights between South America and Southern Africa, a large fraction of the flight routes within this region of the world have ice clouds not only accompanied by $\mathrm{CO}$ anomalies, but also have EIE with the CO that is associated with air lofted from surface sources. The black star markers are cities with populations larger than ten million, i.e., megacities (these are listed along with their locations and populations in the Supplementary Material, in Table SM1).

Figure 8 further clarifies the regional distribution of the average $\mathrm{CO}$ anomalies, for all ice clouds, separated by the type of emission source, similar to how the $\mathrm{CO}$ data are presented in Fig. 4. The average anomalies, when associated with ice clouds, are similar to those with all CO, i.e. BB emissions exceed UP in the AO and PIA but there are no

305 differences with respect to these same sources in SHAA or NHAA. The largest anomalies of total CO, i.e., when both BB and UP are contributing, are over the PIA regions. Average values and standard deviations are shown in Table 2.

Figure 9 summarizes the ice cloud events that are collocated with CO anomalies, similar to what is shown in Fig. 5, but differentiated by ice clouds with EIE (Fig. 9a) and non-EIE (Fig. 9b) and related to regions that are the source of 310 the $\mathrm{CO}$ anomalies. The EIE in the AO and PIA regions are equally influenced by CO from the PIA, between 70 and $75 \%$. A further $20 \%$ of the EIE contain CO anomalies (Other) that originate in regions located northward of $30^{\circ} \mathrm{N}$, beyond the area of interest (Fig. 9a). Seventy percent of the CO in EIE over NHAA and SHAA originates from the surface under the same region where the clouds were encountered (Fig. 9b). The frequency distributions of the nonEIE with CO (Fig. 9b) have the same patterns as the EIE, with only slightly different magnitudes of the source contributions.

\subsection{Discussion}

Based on the results that are presented in the previous section, we can conclude that the sources of a large fraction of the $\mathrm{CO}$ that is encountered within the sampled ice clouds are biomass burning and urban emissions at the surface. We will now link these emissions to the primary source regions and discuss how the CO produced in these areas is able to reach aircraft altitudes. This linkage is an important key to supporting our hypothesis that a significant number of ice clouds in the tropics and sub-tropics are formed on CCN or INP produced by BB and fossil fuel combustion.

\subsection{CO surface sources and CCN/INP composition}

325 MODIS measurements (in Aqua and Terra) provide thermal anomalies that are used to derive the fire radiative power (in MW), over the years 2011-2019, associated with areas of enhanced emissions. Figure SM1 in the supplementary 
material shows the spatial distribution of the seasonal variablity of the FRP. These figures show the seasonality of biomass burning in different regions of the world. Note that in Africa, most of the emissions are from July through October (Fig. SM1) in the southern hemisphere, moving to the northern hemisphere in November and December. Over Asia, in particular southeast Asia, the primary burning season is from July through October.

We highlight here only the spatial distribution for July and December in Figure 10, in which the magenta and blue correspond to the more intense fires. Also drawn on these maps are the EIE (black markers) from IAGOS flights during the same time periods. The EIE over Africa are north of the BB areas in July; however, as discussed below in section 5, and as was illustrated in Fig. 5, the $\mathrm{CO}$ anomalies encountered in the NH Africa ice clouds have some of their sources located in SH Africa. The transport of BB emissions from the surface in one region to the ice clouds in another region is further highlighted in the next section, 4.2, where we discuss vertical motions. In December there are EIE along the airline route between Northern Africa and South America, these would appear to be related to enhanced emissions BB in Northern Africa and westward transport, as is discussed below. The co-location of EIE and BB in Southeast Asia, particularly in the region of Vietnam and Indonesia, is clearly observed.

The CO anomaly analysis identifies the potential sources of the air that is mixed with ice clouds, but cannot provide any information about the particles co-emitted with CO. The AOD derived from the MODIS on the Aqua satellite measures the particle light extinction in a vertical column of air, which is a very good indicator of the particle mass in that column. The AOD, shown in Fig. 11, compared with the fire maps and the CO anomalies and ice cloud distributions, provides a correlative link between the particles that are the source of CCN/INP for the ice crystals and the source of emissions. Note that AOD is derived after filtering for clouds so that only aerosol particles are contributing to the light extinction, and values shown in Fig. 11 have been normalized to the maximum value measured in the domain shown.

Looking first at Africa and comparing AOD and fire radiative power, while the widespread regions of biomass burning in western Africa in December (Fig 10b) are not directly associated with EIE, the AOD spatial distribution (Fig. 11b) indicates a westward transport of BB emissions over the Atlantic by the dominant upper-level winds. The ice clouds sampled by aircraft near deep convection in the Atlantic Intertropical Convergence Zone (ITCZ) show several EIE which are associated with high AOD originated over the BB in Africa, supported by the modelling to determine CO source collocated with EIE. In contrast, AOD in July (Fig. 11a) is high over northern Africa but not collocated with $\mathrm{BB}$, which is virtually absent there. Nevertheless, this region adjoins the area of most frequent EIE indicating high aerosol particle concentrations associated with the ice clouds. but in July, high AOD observed in the same region, and particularly over the Indian Ocean (Fig. 11a), are clearly unrelated to BB emissions when compared with the FRP mapped in Fig. 10a. 
The proximity of the EIE to regions with large magnitude of AOD suggests that these clouds have likely formed on aerosol particles from relatively nearby sources. However, the maps suggest that these BB emissions are the source of some, but not all of the particles that lead to EIE. Recall, that the back trajectory analysis indicated that UP was another significant source of $\mathrm{CO}$, but additional information is needed to better support the argument that UP is a source of aerosol particles as well as of CO.

The concentration of different particle composition (considered as external mixtures) is derived from the the MERRA2 reanalysis, as detailed in the methodology. Figure 12 show the spatial distribution of the mass concentrations of particle mass by composition, averaged over the atmospheric layer from $8-12 \mathrm{~km}$ and converted to standard temperature and pressure in dimensions of grams per cubic meters. The composition considered relevant for this study are dust (Fig. 12a and b), the sum of organic and black carbon (Fig. 12c and d) and sulfate (Fig. 12e and f). Only the months of July and December are shown here to relate directly with sources of BB (Fig. 10) and AOD (Fig. 11); all months are shown in the supplementary material (Fig. SMx). The seasonality of the particle composition in the upper troposphere (at altitudes between 8 and $12 \mathrm{~km}$ ) is quite evident, especially with the dust and sulfate distributions that are much larger in concentration during July than during December.

A comparison of the maps of particle composition (Fig. 12) and AOD (Fig. 11) reveals that the high AOD over northern Africa (Fig. 11a) in July is collocated with the high dust concentrations $\left(>10 \mu \mathrm{g} \mathrm{m}^{-3}\right)$ in the upper troposphere and also with EIE over the same area. This strongly suggests that the EIE in this region is likely related to dust, in addition to the BB that is also adjoining this region during July and whose presence is confirmed by the CO analysis. Not only is northern Africa inundated with dust at flight level, but the region over the Arabian Peninsula, the Indian Ocean, India and China also have dust concentrations in excess of $10 \mu \mathrm{gm}^{-3}$, coinciding with significant AOD. The EIE are also clustered in this dust belt band, particularly clear over India. The presence of dust in the vicinity of EIE

385 is very significant because dust particles are very good nuclei for forming ice by deposition of water vapor directly on their surfaces (Ref. DeMott??).

The high OC/BC concentrations in the upper troposphere $\left(>10 \mu \mathrm{gm}^{-3}\right)$ near the ITCZ in central Africa (Fig. 12c) in July and in December over Africa and South America (Fig. 12d), reflect the similarly large AOD in these regions (Fig.

390 11b) and they overlap with the area of high FRP during the same time periods in July (Fig. 10a) and December (Fig. 10b). Hence, the particles associated with the BB emissions are clearly linked with the fires, $\mathrm{CO}, \mathrm{OC} / \mathrm{BC}$ and EIE.

In a similar analysis, the high concentrations of sulfate particles in the upper troposphere in July (Fig. 12e), which stretch from the western Africa to the Pacific Ocean east of Japan, are mixed with dust over part of the region (Africa, Arabia and partially India) but dominate the particle composition over southern China, Thailand, Cambodia, Vietnam and Japan. These high concentrations are partially reflected in the larger AOD, but the particularly striking feature are the many EIE in the region over eastern Asia. Recall that the CO anomaly analysis also identified UP as the primary source of $\mathrm{CO}$ in the ice clouds over this area. 
The final piece of the ice cloud and EIE puzzle to be evaluated is the mechanism by which the CO and associated particles are lofted to the UT where they are encountered by aircraft. Deep convection, orographic barriers or frontal systems are processes that can transport surface pollutants into the UT. The upper air wind divergence (at $200 \mathrm{hPa}$ ) is directly associated with underlying vertical motions. Figure 13 shows the July and December maps of upper-level divergence, averaged over the years 2011-2019, and with EIE indicated by black markers.

The seasonal variation is clearly recognizable over the Atlantic, with the highest values in December, also the month where the largest number of EIE are encountered in the same region. The large divergence over Africa (corresponding to the ITCZ) shifts from the northern hemisphere in July to well-south of the equator in December. Particularly significant is the cluster of EIE over this region of upper-level divergence in July, while virtually no such events exist in December, except directly over the western coast where the divergence is also large. The lack of EIE over south central Africa in December, even when there is large upper-level divergence, is due to the scarcity of flights. This source of particles is north of the region of major updrafts so that only the coastal region downwind of the BB emissions is impacted by these emissions.

There is much less seasonal variation over Asia where we observe appreciable divergence that corresponds to the locations of the EIE during July and December. Although the amount of sulfate is much more pronounced in July than in December, there is an increase in the $\mathrm{OC} / \mathrm{BC}$ during December over this region as well as persistent dust and sulfate particles. Hence, with the widespread vertical motion, there is sufficient uplift of material from the surface to transport $\mathrm{CCN}$ and INP to flight levels in July and December.

The identification of anomalous $\mathrm{CO}$ in ice clouds can be almost unambiguously linked to surface sources and vertical motion. Additional evidence for vertical motions are shown in the maps of OLR (Figs. 13 c,d) and lightning count

(Figs. 13 e,f). Low values of OLR are a very good proxy for the presence of clouds, indicating that the long wave emissions are dominated by cloud tops with very low temperature, characteristic of deep convection and ice clouds. In Figs. 13 c,d over the Atlantic ITCZ, where there are many EIE, the upper-level divergence is closely related to underlying vertical motions coinciding with low values of OLR due to the presence of clouds, and the AOD is high, indicative of large mass concentrations of particles.

The regions of high lightning counts are in close correspondence with the low OLR and large upper-level divergence, further reinforcing the correlative relationship between these independent indicators of vertical motion and the presence of clouds. Note the large clusters of EIE located in the same regions of lightning high frequency, low OLR and elevated divergence. 
Ice clouds, in addition to having a major influence on climate through their interactions with incoming and outgoing radiation, are also a potential hazard to commercial aviation as a result of the clogging of air data sensors or by being ingested into engines, a condition that can lead to engine flameout or rollback (e.g., Mason et al., 2006; Grzych and Mason, 2009; Mason and Grzych, 2011; Bravin, et al., 2015; Haggerty et al., 2019; Bravin and Strapp, 2019). Figure events reported by pilots from 1990 to 2019 (Bravin and Strapp, 2019). The map shown in Fig. 14, with the ICI events marked by the blue filled circles, is reprinted with permission from the authors and the Society of Automotive Engineers (SAE) International Journal on Advances \& Current Practices in Mobility.

445 The juxtaposition of nearly all of the ICI events with the EIE underscores the importance of the link between hazardous flying conditions and the presence of ice clouds with extremely high crystal concentrations, clouds that in this current study have been associated with ground based emissions of anthropogenic $\mathrm{CO}$ and aerosol particles.

\subsection{Relationship with previous studies}

The results that we have presented provide a framework for linking ice clouds in general, and EIE in particular, to surface sources of dust, BB and UP in tropical latitudes. However, this study lacks in situ measurements of the actual ice crystal residuals that could identify the composition of the ice nuclei, we are unable to unequivocally conclude that extreme ice events are due to emissions from BB and UP. Instead, we will place our results in the context of studies of cirrus clouds in the regions similar to those we have reported here. Krämer et al (2020) provide a comprehensive summary of the microphysical properties of cirrus clouds related to where they are found and to the aerosols from which they form. The ice clouds measured by the BCP in the latitude band of $\pm 30^{\circ}$ are most likely those that have been designated as liquid in origin. According to the Krämer et al. (2016, 2020), Luebke et al. (2016) and Costa et al. (2016), liquid-origin ice clouds are usually composed of high concentrations of water droplets that froze either homogeneously or heterogeneously at a lower altitude. Although some of the ice might have formed on INP, the greater abundance of CCN relative to INP would suggest that the ice formation process is through droplet freezing. Many laboratory, cloud chamber and field studies have shown that some fraction of the BB and UP aerosol are hygroscopic and can serve as CCN, while fewer studies have demonstrated the efficacy of these types of particles as INPs. The liquid-origin clouds that formed in the tropics, as discussed by Krämer et al. $(2016,2020)$, were related primarily to deep convection and anvil outflow, similar to what we have reported here.

\subsection{Conclusions and recommendations}

Measurements made with Backscatter Cloud Probes flown on eight Airbus 330/340 passenger airliners from December 2011 to March 2020, as part of the In-Service Aircraft for a Global Observing System (IAGOS), were analyzed to assess the properties of ice clouds in a region bounded by $\pm 30^{\circ}$ latitude and $-50^{\circ}$ to $180^{\circ}$ longitude. A total of 67172 ice clouds were sampled during 22857 flights, representing 1483 hours in cloud. Approximately $20 \%$ of 
these clouds (6490) had number concentrations larger than $5000 \mathrm{~L}^{-1}$, a concentration defined here as an extreme ice event (EIE).

The potential influence of anthropogenic emissions was evaluated using SOFT-IO, a model that incorporates back trajectory analysis to identify anomalous levels of carbon monoxide (CO) in the air masses sampled by the aircraft. The CO anomalies, values that exceeded a background concentration at flight level, were averaged into $0.25^{\circ}$ by $0.25^{\circ}$ grid cells and compared with ice crystal concentrations averaged into the same cells. Of all the cells that had positive $\mathrm{CO}$ anomalies or ice concentrations $>50 \mathrm{~L}^{-1}$ along the aircraft flight tracks, $52 \%$ of the cells had CO anomalies with no clouds, $10 \%$ had clouds with no $\mathrm{CO}$ anomalies, and $48 \%$ had concurrent observations of clouds and $\mathrm{CO}$ anomalies. When only EIE clouds were evaluated, the numbers were $75 \%, 4 \%$ and $21 \%$, respectively. In other words, when considering all clouds, $79 \%$ were accompanied by positive CO anomalies while only including EIE clouds, $84 \%$ of these had anomalous concentrations of CO. Hence, there is nothing that would suggest that EIE clouds are being influenced significantly more often than non-EIE clouds.

485 The modal frequency of the temperature EIE clouds was five degrees colder than non-EIE clouds; however, this difference is insignificant when taking the temperature variance into account. Likewise, neither the differences in EIE over the study region or the differences in the magnitude of $\mathrm{CO}$ anomalies between EIE and non-EIE clouds were significant.

490 We conclude that the two, primary factors that are associated with the EIE encounters are the proximity to sources of dust, $\mathrm{OC} / \mathrm{BC}$ or sulfate combined with strong vertical motions in deep convective clouds. These conclusions are drawn from the synthesis of information from multiple, independent analyses:

1. In situ observations of cloud ice concentrations by the IAGOS BCP.

2. In situ observations of CO mixing ratios by the IAGOS gas analyzers coupled with results from the SOFTIO back trajectories calculations that linked $\mathrm{CO}$ anomalies along the flight track with surface emissions.

3. Maps of fire radiative power and AOD derived from satellite imagery that could be linked to the flight level $\mathrm{CO}$ from the back trajectory analysis.

4. Maps of aerosol particle composition derived from MERRA-2 that were linked to the maps of AOD, fires and flight level CO.

5. Maps of upper air divergence and OLR derived from the ERA5 that corresponded to regions of EIE and high AOD

6. Maps of lightning frequency derived from the World Wide Lightning Location Network (WWLN) associated with deep convection that overlapped with the regions of upper air divergence, OLR and EIE

505 A qualitative comparison of regions with ice crystal icing (ICI) events and EIE shows an unmistakable spatial correspondence that underscores the potential importance of EIE on commercial aviation. The IAGOS program encountered 6490 EIE in a ten year period, or approximately 650 per year. This seems small compared to the number 
of IAGOS 22857 flights during this same period, i.e., 2285 flights yearly, yet this implies that almost $30 \%$ of the flights encountered an EIE, assuming that the data are from only a single EIE encountered per flight. The significance of this number becomes clearer when taking into account the more than a million international flights made per year when potentially more than 300,000 of those flights might eventually encounter EIE. This statistic, while lacking robust validation, is sufficiently alarming to highlight the need for better forecasting of ice clouds along flight corridors, in general, and the probability of EIE, in particular.

515 The results that we have presented here have shown how anthropogenic emissions as well as desert dust are lofted by strong convergence at the surface and UT divergence, leading to the formation of ice clouds and EIE, which in turn are responsible for the ICI. These results explain the prevalence of ICI and EIE in the tropics around the ITCZ, especially over Africa and Asia, which is highlighted in the BCP measurements compared with pilot results (Fig. 14). More recently, Rugg et al. (2021) analyzed 11 years of Cloudsat and CALIOP measurements and showed that, on 520 average, more than $2 \%$ of the UT clouds in this region contain ice water content $>1.0 \mathrm{gm}^{-3}$. Hence, a better knowledge of the sources of aerosol particles, their composition and their concentrations, will provide valuable information that can improve flight planning and the forecast of potential areas of EIE.

The current study has established a pathway that links extreme ice concentrations in ice clouds and the surface emissions of particles from biomass burning and fossil fuel combustion; however, there remain a number of critical, unresolved questions:

- What is the relationship between ice cloud $\mathrm{CO}$ and the properties of the $\mathrm{CCN}$ or INP from which the crystals formed?

- What is the relationship between age of the $\mathrm{CO}$ and the ice crystal concentrations, in particular, what leads to the evolution of EIE clouds?

- What additional information is needed to accurately forecast ice clouds in general and EIE in particular, not only for improved flight safety, but for a better understanding of the climate impact of these clouds?

In final summary, the results presented in this study emphasize the importance of programs like IAGOS for expanding the data base of cloud measurements and the need to broaden such programs to include more aircraft to provide a more complete spatial and temporal climatology.

\subsection{Data availability}

The BCP, CO and SOFT-IO CO trajectories are all downloadable, free of charge, from the IAGOS web site http://www.iagos-data.fr/. The AOD and fire radiative power are standard products from the Moderate Resolution

540 Imaging Spectroradiometers (MODIS) sensors on the Aqua and Terra satellites and are available free of charge, from https://modis.gsfc.nasa.gov/. The data used to generate the maps of upper air divergence and OLR used the new generation reanalysis from the European Centre for Medium-Range Weather Forecasts (ECMWF), ERA5 (ecmwf.int/en/forecasts/datasets/reanalysis-datasets/era5) and the data used to create the maps of aerosol composition 
was downloaded from the MERRA-2, produced by NASA's Global Modeling and Assimilation Office (https://gmao.gsfc.nasa.gov/). Non-real time lightning data is available from the WWLLN website (http://wwlln.net/) at no cost for users who supply data to this network; otherwise, there is a charge for the data.

\subsection{Author contributions}

Graciela Raga and D. Baumgardner designed the study, interpreted the combined results and wrote the text, D. Baumgardner analyzed the BCP and CO measurements, B. Rios provided the analisis and associated figures from the

550 Terra and Aqua MODIS data, Y. Díaz-Esteban extracted the information from the ERA5 reanalysis and generated the maps, A. Jaramillo evaluated the MERRA-2 and WWLLN data and drew the associated maps of aerosol composition and lightning frequency, M. Gallager and G. Lloyd supplied the BCP files and B. Sauvage and P. Wolff assisted with the interpretation and analysis of the SOFT-IO trajectories.

\subsection{Acknowledgements}

555 IAGOS gratefully acknowledges financial support during its preparation, implementation and operation phase from the European Commission in FP6 and FP7 programmes, national research programmes in Germany (BMBF), France (INSU-CNRS, MESR, CNES) and UK (NERC), in addition to institutional resources in Germany (Helmholtz Association, Max-Planck-Society, Leibniz Association), France (Universite de Toulouse, Meteo-France) and the UK (University of Manchester, University of

560 Cambridge), and the continuing support by participating airlines (Deutsche Lufthansa, Air-France, Iberia in Europe, China Airlines and Cathay Pacific in Asia). The authors also thank the World Wide Lightning Location Network (http://wwlln.net), a collaboration among over 50 universities and institutions, for providing the lightning location data used in this paper and gratefully acknowledge the European Centre for Medium-Range Weather Forecasts (ECMWF) and the Earth Observing System Data and Information System (EOSDIS) at NASA for data availability.

\subsection{References}

Beswick, K., Baumgardner, D., Gallagher, M., Volz-Thomas, A., Nedelec, P., Wang, K. Y., and Lance, S.: The backscatter cloud probe-a compact low-profile autonomous optical spectrometer, Atmospheric Measurement Techniques, 7(5), 1443-1457, https://doi.org/10.5194/amt-7-1443-2014, 2014.

Beswick, K., Baumgardner, D., Gallagher, M., Raga, G. B., Minnis, P., Spangenberg, D. A., et al.: Properties of small cirrus ice crystals from commercial aircraft measurements and implications for flight operations, Tellus B: Chemical and Physical Meteorology, 67(1), 27876, https://doi.org/10.3402/tellusb.v67.27876, 2015.

Bocquet, M., Elbern, H., Eskes, H., Hirtl, M., Žabkar, R., Carmichael, G., Flemming, J., Inness, A., Pagowski, M., Camaño, J., Saide, P., Jose, R., Sofiev, M., Vira, J., Baklanov, A., Carnevale, C., Grell, G. and Seigneur, C.: Data assimilation in atmospheric chemistry models: current status and future prospects for coupled chemistry meteorology models. Atmos. Chem. Phys., 15(10), 5325-5358. doi:/10.5194/acp-15-5325-2015, 2015 
Bravin, M., Strapp, J., and Mason, J.: An Investigation into Location and Convective Lifecycle Trends in an Ice Crystal Icing Engine Event Database, SAE Technical Paper 2015-01-2130, doi:10.4271/2015-01-2130, 2015

Bravin, M., and Strapp, J.W.: A Continuing Investigation of Diurnal and Location Trends in an Ice Crystal Icing Engine Event Database, SAE Int. J. Advances \& Curr. Prac. in Mobility 2(1):90-105, doi:10.4271/2019-011964, 2020.

Brooks, S. D., K. Suter, and L. Olivarez, 2014: Effects of chemical aging on the ice nucleation activity of soot and polycyclic aromatic hydrocarbon aerosols. J. Phys. Chem., 118A, 10 036- 10 047, doi:10.1021/jp508809y.

Costa, A., Meyer, J., Afchine, A., Luebke, A., Günther, G., Dorsey, J. R., Gallagher, M. W., Ehrlich, A., Wendisch, M., Baumgardner, D., Wex, H., and Krämer, M.: Classification of Arctic, midlatitude and tropical clouds in the mixed-phase temperature regime, Atmos. Chem. Phys., 17, 12219-12238, https://doi.org/10.5194/acp-1712219-2017, 2017. Cussac, M., Marécal, V., Thouret, V., Josse, B., and Sauvage, B.: The impact of biomass burning on upper tropospheric carbon monoxide: a study using MOCAGE global model and IAGOS airborne data, Atmos. Chem. Phys., 20, 9393-9417, https://doi.org/10.5194/acp-20-9393-2020, 2020

Ding, K., Liu, J., Ding, A., Liu, Q., Zhao, T. L., Shi, J., Han, Y., Wang, H., and Jiang, F.: Uplifting of carbon monoxide from biomass burning and anthropogenic sources to the free troposphere in East Asia, Atmos. Chem. Phys., 15, 2843-2866, https://doi.org/10.5194/acp-15-2843-2015, 2015.

Ditas, J., Ma, N., Zhang, Y., Assmann, D., Neumaier, M., Riede, H., Karu, E., Williams, J., Scharffe, D., Wang, Q., Saturno, J., Schwarz, J. P., Katich, J. M., McMeeking, G. R., Zahn, A., Hermann, M., Brenninkmeijer, C. A. M., Andreae, M. O., Pöschl, U., Su, H., and Cheng, Y.: Strong impact of wildfires on the abundance and aging of black carbon in the lowermost stratosphere, PNAS, 115 (50) E11595-E11603, 2018.

Dowden, R. L., J. B. Brundell, and C. J. Rodger, VLF lightning location by time of group arrival (TOGA) at multiple sites, J. Atmos. Sol. Terr. Phys., 64, 817-830, 2002

600 Gelaro, R., McCarty, W., Suárez, M. J., Todling, R., Molod, A., Takacs, L., ... Zhao, B. (2017). The Modern-Era Retrospective Analysis for Research and Applications, Version 2 (MERRA-2). J. Climate, 30(14), 5419-5454. doi: 10.1175/jcli-d-16-0758.1

Gorbunov, B., A. Baklanov, N. Kakutkina, H. Windsor, and R. Toumi, 2001: Ice nucleation on soot particles. J. Aerosol Sci., 32, 199-215, doi:10.1016/S0021-8502(00)00077-X.

605 Grawe, S., S. Augustin-Bauditz, S. Hartmann, L. Hellner, J. B. C. Pettersson, A. Prager, F. Stratmann, and H. Wex, 2016: The immersion freezing behavior of ash particles from wood and brown coal burning. Atmos. Chem. Phys., 16, 13 911-13 928, doi:10.5194/acp-16-13911-2016.

Hersbach, H., and Coauthors : Era5 hourly data on pressure levels from 1979 to present, Tech. rep., Copernicus Climate Change Service (C3S) Climate Data Store (CDS), doi:10.24381/cds.bd0915c6, 2018.

610 Gasparini, B., Meyer, A., Neubauer, D., Münch, S., \& Lohmann, U.. Cirrus Cloud Properties as Seen by the CALIPSO Satellite and ECHAM-HAM Global Climate Model, Journal of Climate, 31(5), 2018.

Giglio, L., Schroeder, W., and Justice, C. O.: The collection 6 MODIS active fire detection algorithm and fire products, Remote Sens. Environ, 178, 31-41, https://doi.org/10.1016/j.rse.2016.02.054, 2016. 
Grzych, M., and Mason, J.: Weather Conditions Associated with Jet Engine Power Loss and Damage due to the Ingestion of Ice Particles: What We've Learned Through 2009, 14th Conf. on Aviation, Range, and Aerospace Meteorology, Atlanta, GA, Amer. Meteor. Soc., 6.8. https://ams.confex.com/ams/pdfpapers/165923.pdf, 2010.

Haggerty, J., Defer, E., De Laat, A., Bedka, K., Moisselin, J-M., Potts, R., Delanoë, J., Parol, F., Grandin, A., and Divito, S.: Detecting Clouds Associated with Jet Engine Ice Crystal Icing, Bull. Amer. Meteor. Soc., 31-40, https://doi.org/10.1175/BAMS-D-17-0252.1, 2019.

Hersbach, H., Bell, B., Berrisford, P., Biavati, G., Horányi, A., Muñoz Sabater, J., Nicolas, J., Peubey, C., Radu, R., Rozum, I., Schepers, D., Simmons, A., Soci, C., Dee, D., Thépaut, J-N.: ERA5 hourly data on single levels from 1979 to present. Copernicus Climate Change Service (C3S) Climate Data Store (CDS), doi: 10.24381/cds.adbb2d47, 2018.

Hirsch, E. and Koren, I.: Record-breaking aerosol levels explained by smoke injection into the stratosphere, Science 371, 1269-1274, 2021.

Jahl, L. G., Brubaker, T. A., Polen, M. J., Jahn, L. G., Cain, K. P., Bowers, B. B., ... Sullivan, R. C.: Atmospheric aging enhances the ice nucleation ability of biomass-burning aerosol. Science Advances, 7(9), eabd3440. https://doi.org/10.1126/sciadv.abd3440, 2021.

Kanji, Z. A., Ladino, L. A., Wex, H., Boose, Y., Burkert-Kohn, M., Cziczo, D. J., and Krämer, M.: Overview of ice nucleating particles, Meteorol. Monogr., 58, 1.1-1.33, https://doi.org/10.1175/AMSMONOGRAPHS-D-160006.1, 2017.

Kärcher B. Formation and radiative forcing of contrail cirrus. Nat Commun., 9(1):1824. 2018. doi:10.1038/s41467018-04068-0

Kärcher B, Burkhardt U, Ponater M, Frömming C. Importance of representing optical depth variability for estimates of global line-shaped contrail radiative forcing. Proc Natl Acad Sci U S A. 107(45):19181-4. doi: 10.1073/pnas.1005555107, 2010

Kaufman, Y. J., Justice, C. O., Flynn, L. P., Kendall, J. D., Prins, E. M., Giglio, L., Ward, D. E., Menzel, W. P., and Setzer, A. W.: Potential global fire monitoring from EOS-MODIS, J. Geophys. Res. Atmos, 103(D24), 3221532238, doi:10.1029/98JD01644, 1998.

640 Knopf, D. A., Alpert, P. A. and Wang, B.: The Role of Organic Aerosol in Atmospheric Ice Nucleation: A Review. ACS Earth and Space Chemistry, 2(3), 168-202. https://doi.org/10.1021/acsearthspacechem.7b00120, 2018

Krämer, M., Rolf, C., Luebke, A., Afchine, A., Spelten, N., Costa, A., Meyer, J., Zoeger, M., Smith, J., Herman, R. L., Buchholz, B., Ebert, V., Baumgardner, D., Borrmann, S., Klingebiel, M., and Avallone, L.: A microphysics guide to cirrus clouds - Part 1: Cirrus types, Atmospheric Chemistry and Physics, 16, 3463-3483, doi:10.5194/acp-16-3463-2016, 2016.

Krämer, M., Rolf, C., Spelten, N., Afchine, A., Fahey, D., Jensen, E., Khaykin, S., Kuhn, T., Lawson, P., Lykov, A., Pan, L. L., Riese, M., Rollins, A., Stroh, F., Thornberry, T., Wolf, V., Woods, S., Spichtinger, P., Quaas, J., and Sourdeval, O.: A Microphysics Guide to Cirrus - Part II: Climatologies of Clouds and Humidity from Observations, Atmos. Chem. Phys. Discuss., https://doi.org/10.5194/acp-2020-40, in review, 2020. 

Clouds on a Global Scale, Atmosphere, 12(1), 41, https://doi.org/10.3390/atmos12010041, 2021.

Luebke, A. E., Afchine, A., Costa, A., Grooß, J.-U., Meyer, J., Rolf, C., Spelten, N., Avallone, L. M., Baumgardner, D., and Krämer, M.: The origin of midlatitude ice clouds and the resulting influence on their microphysical properties, Atmos. Chem. Phys., 16, 5793-5809, https://doi.org/10.5194/acp-16-5793-2016, 2016.

Mason, J., Strapp, W., and Chow, P.: The Ice Particle Threat to Engines in Flight, in 44th AIAA Aerospace Sciences Meeting, 2445-2465, v4, 2006.

Mason, J., and Grzych, M.: The Challenges Identifying Weather Associated with Jet Engine Ice Crystal Icing, SAE Technical Paper 2011-38-0094, Doi:10.4271/2011-38-0094, 2011.

Nédélec, P., Cammas, J.-P., Thouret, V., Athier, G., Cousin, J.-M., Legrand, C., Abonnel, C., Lecoeur, F., Cayez, G., and Marizy, C.: An improved infrared carbon monoxide analyser for routine measurements aboard commercial Airbus aircraft: technical validation and first scientific results of the MOZAIC III programme, Atmos. Chem. Phys., 3, 1551-1564, https://doi.org/10.5194/acp- 3-1551-2003, 2003.

Nédélec, P., Blot, R., Boulanger, D., Athier, G., Cousin, J.-M., Gautron, B., Petzold, A., Volz-Thomas, A., and Thouret, V.: Instrumentation on commercial aircraft for monitoring the atmospheric composition on a global scale: the IAGOS system, technical overview of ozone and carbon monoxide measurements, Tellus B: Chemical and Physical Meteorology, 67:1, 27791, https://doi.org/10.3402/tellusb.v67.27791, 2016.

Osman, M. K., Tarasick, D. W., Liu, J., Moeini, O., Thouret, V., Fioletov, V. E., Parrington, M., and Nédélec, P.: Carbon monoxide climatology derived from the trajectory mapping of global MOZAIC-IAGOS data, Atmos. Chem. Phys., 16, 10263-10282, https://doi.org/10.5194/acp-16-10263-2016, 2016.

Petetin, H., Sauvage, B., Parrington, M., Clark, H., Fontaine, A., Athier, G., Blot, R., Boulanger, D., Cousin, J.-M., Nédélec, P., and Thouret, V.: The role of biomass burning as derived from the tropospheric CO vertical profiles measured by IAGOS aircraft in 2002-2017, Atmos. Chem. Phys., 18, 17277-17306, https://doi.org/10.5194/acp18-17277-2018, 2018.

Petetin, H., Thouret, V., Fontaine, A., Sauvage, B., Athier, G., Blot, R., Boulanger, D., Cousin, J.-M., and Nédélec, P.: Characterising tropospheric $\mathrm{O}_{3}$ and $\mathrm{CO}$ around Frankfurt over the period 1994-2012 based on MOZAICIAGOS aircraft measurements, Atmos. Chem. Phys., 16, 15147-15163, https://doi.org/10.5194/acp-16-151472016, 2016.

Petzold, A., Thouret, V., Gerbig, C., Zahn, A., Brenninkmeijer, C. A. M., Gallagher, M. and co-authors, Global-scale atmosphere monitoring by in-service aircraft - current achievements and future prospects of the European Research Infrastructure IAGOS, Tellus B: Chemical and Physical Meteorology, 67:1, 28452. http://dx.doi.org/10.3402/tellusb.v67.28452, 2015.

Popovicheva, O., E. Kireeva, N. Persiantseva, T. Khokhlova, N. Shonija,V.Tishkova, andB.Demirdjian, 2008: Effect of soot on immersion freezing of water and possible atmospheric implications. Atmos. Res., 90, 326-337, doi:10.1016/j.atmosres.2008.08.004 
685 Randles, C.A., Silva, A. M. d., Buchard, V., Colarco, P. R., Darmenov, A., Govindaraju, R., Flynn, C.J. (2017). The MERRA-2 Aerosol Reanalysis, 1980 Onward. Part I: System Description and Data Assimilation Evaluation. J. Climate, 30(17), 6823-6850. doi:10.1175/jcli-d-16-0609.1

Remer, L. A., Tanré, D., and Kaufman, Y. J.: Algorithm for remote sensing of tropospheric aerosol from MODIS: Collection 005, Report Product ID: MOD04/MYD04 ATBD C005_rev1, Greenbelt, Maryland, 2009.

Rugg, A., Haggerty, J. and Protat, A.,: Global and Regional Patterns in High Ice Water Content Conditions, J. Appl. Meteor. and Clim., 60, 141-155. 2021.

Sauvage, B., Auby, A., and Fontaine, A.: SOFT-IO: SOft attribution using FlexparT and carbon monoxide emission inventories for In-situ Observation database, Aeris, https://doi.org/10.25326/2, 2017a.

Sauvage, B., Fontaine, A., Eckhardt, S., Auby, A., Boulanger, D., Petetin, H., Paugam, R., Athier, G., Cousin, J.-M.,

Darras, S., Nédélec, P., Stohl, A., Turquety, S., Cammas, J.-P., and Thouret, V.: Source attribution using FLEXPART and carbon monoxide emission inventories: SOFT-IO version 1.0, Atmos. Chem. Phys., 17, 1527115292, https://doi.org/10.5194/acp-17-15271-2017, 2017 b.

Sauvage, B., Fontaine, A., and Boulanger, D.: IAGOS ancillary data: CO contributions data, Data set, Aeris, https://doi.org/10.25326/3, 2017c.

700

Sheel, V., Jagat Singh Heet Bisht, Sahu, L., and Thouret, V.: Spatio-temporal variability of CO and O3 in Hyderabad $\left(17^{\circ} \mathrm{N}, 78^{\circ} \mathrm{E}\right)$, central India, based on MOZAIC and TES observations and WRF-Chem and MOZART-4 models, Tellus B: Chemical and Physical Meteorology, 68:1, 30545, DOI: 10.3402/tellusb.v68.30545, 2016.

Sourdeval, O., Gryspeerdt, E., Krämer, M., Goren, T., Delanoë, J., Afchine, A., Hemmer, F., and Quaas, J.: Ice crystal number concentration estimates from lidar-radar satellite remote sensing - Part 1: Method and evaluation, Atmos. Chem. Phys., 18, 14327-14350, https://doi.org/10.5194/acp-18-14327-2018, 2018.

Stohl, A., Forster, C., Frank, A., Seibert, P., and Wotawa, G.: Technical note: The Lagrangian particle dispersion model FLEXPART version 6.2, Atmos. Chem. Phys., 5, 2461-2474, https://doi.org/10.5194/acp-5-2461-2005, 2005.

Umo, N. S., and Coauthors: Ice nucleation by combustion ash particles at conditions relevant to mixed-phase clouds. Atmos. Chem. Phys., 15, 5195-5210, doi:10.5194/acp-15-5195-2015, 2015.

Vernier, J.-P., Fairlie, T. D., Natarajan, M., Wienhold, F. G., Bian, J., Martinsson, B. G., Crumeyrolle, S., Thomason, L. W., and Bedka, K. M.: Increase in upper tropospheric and lower stratospheric aerosol levels and its potential connection with Asian pollution, J. Geophys. Res. Atmos., 120, 1608-1619, doi:10.1002/2014JD022372, 2015. Yamasoe, M.A., Sauvage, B., Thouret, V., Nédélec, P., Le Flochmoen, E., and Barret, B.: Analysis of tropospheric ozone and carbon monoxide profiles over South America based on MOZAIC/IAGOS database and model simulations, Tellus B: Chemical and Physical Meteorology, 67:1, 27884, DOI: 10.3402/tellusb.v67.27884, 2015. 
https://doi.org/10.5194/acp-2021-288

Preprint. Discussion started: 12 May 2021

(C) Author(s) 2021. CC BY 4.0 License.
Atmospheric

Chemistry

and Physics

Discussions

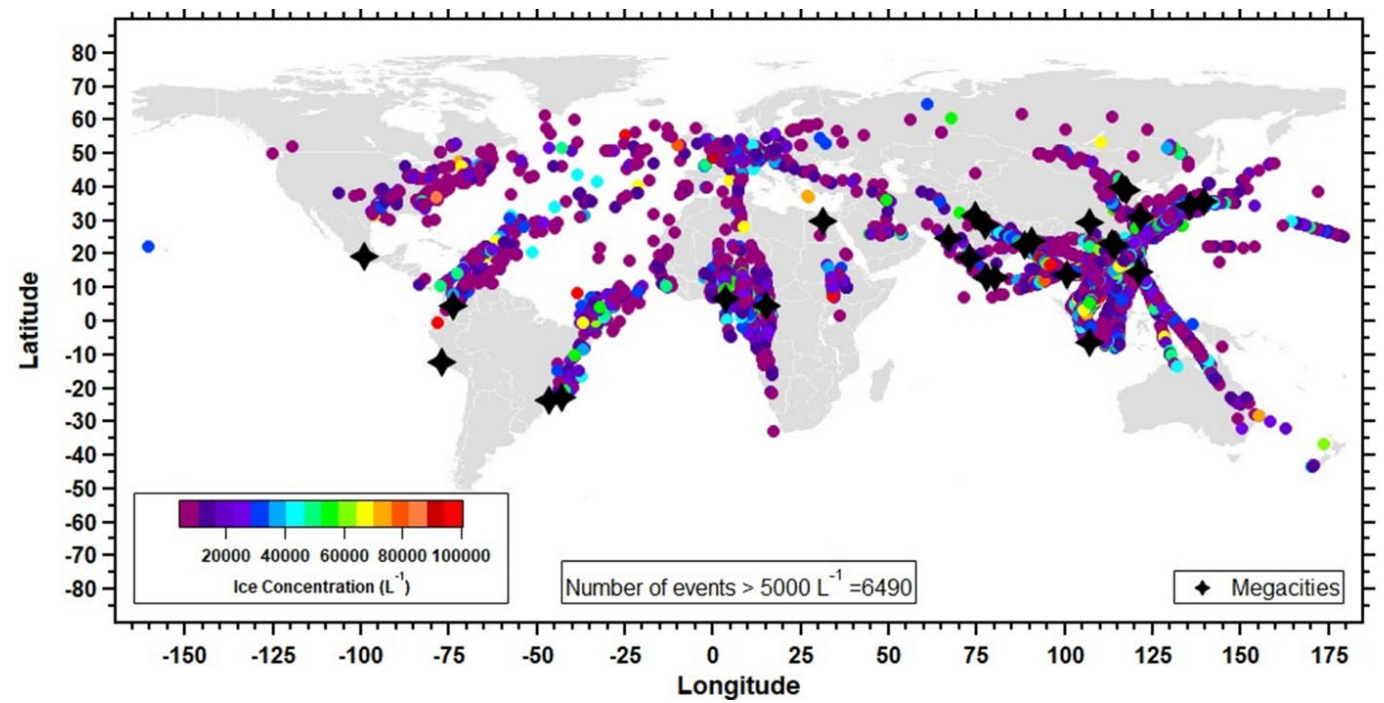

Figure 1. Worldwide distribution of extreme ice events (EIE) when ice clouds concentrations exceed $5000 L^{-1}$ (20112020). The color scale indicates the concentration ice crystal concentration $\left(L^{-1}\right)$. The black stars indicate the location of megacities.
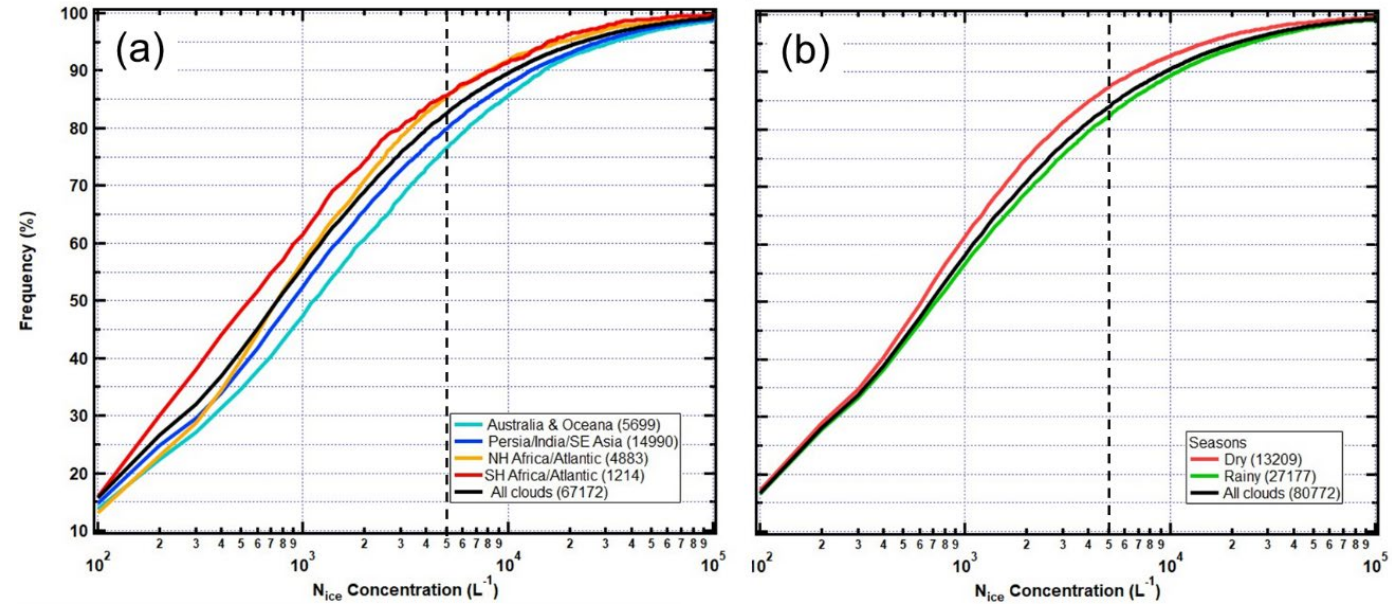

Figure 2. Frequency distribution of $N_{\text {ice }}$ for all measured ice crystal clouds a) by region and b) by dry/rainy season. The vertical dashed lines indicate the Extreme Ice Events (EIE) threshold concentration. 


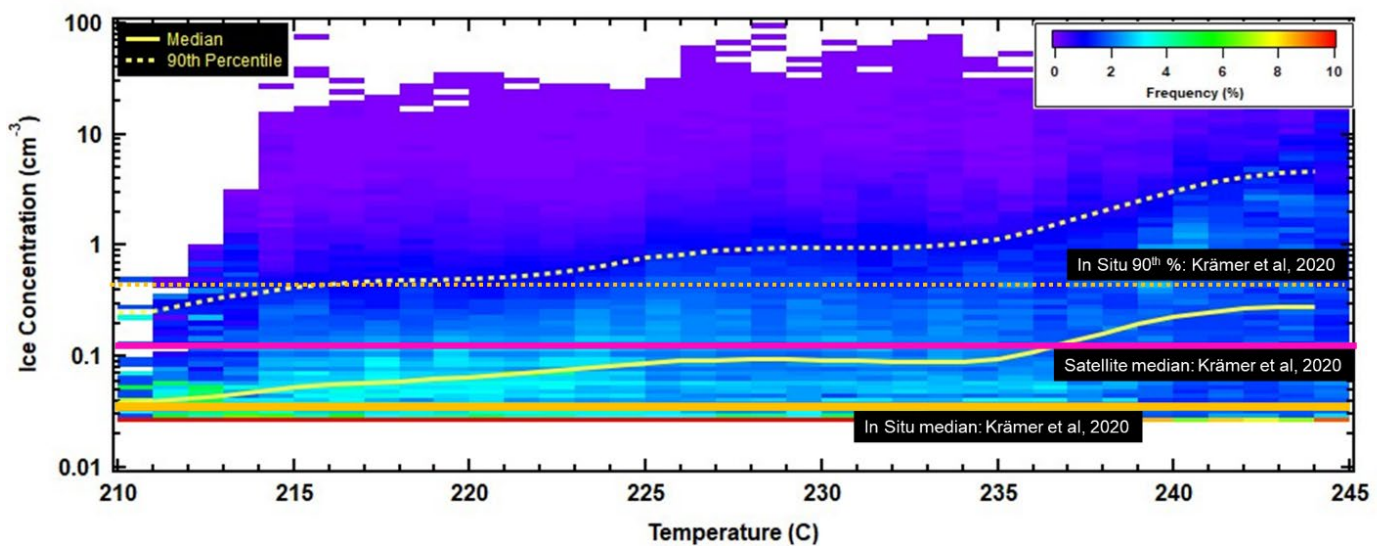

Figure 3. Frequency distribution of cloud ice concentration versus temperatures for all measured ice clouds. The measurements are presented in a format similar to Fig. $7 b$ in Krämer et al. (2020) with the in situ median, satellite derived median and $90^{\text {th }}$ percentiles shown by the horizontal orange, magenta and dashed orange lines, respectively.

The median and $90^{\text {th }}$ percentile values for the data set reported here are shown with the solid and dashed yellow curves, respectively.
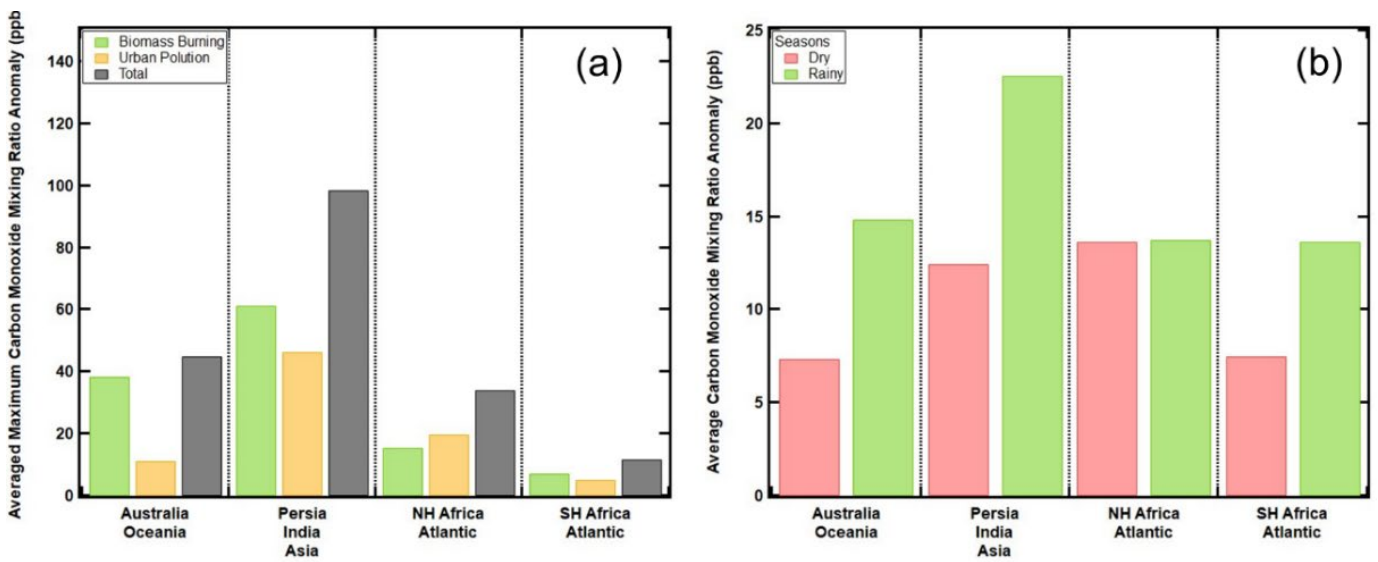

Figure 4. The average CO anomaly as a function of geographical region and (a) source of CO and (b) season of the year. 
https://doi.org/10.5194/acp-2021-288

Preprint. Discussion started: 12 May 2021

(c) Author(s) 2021. CC BY 4.0 License.

(c) (i)
Atmospheric

Chemistry

and Physics

Discussions
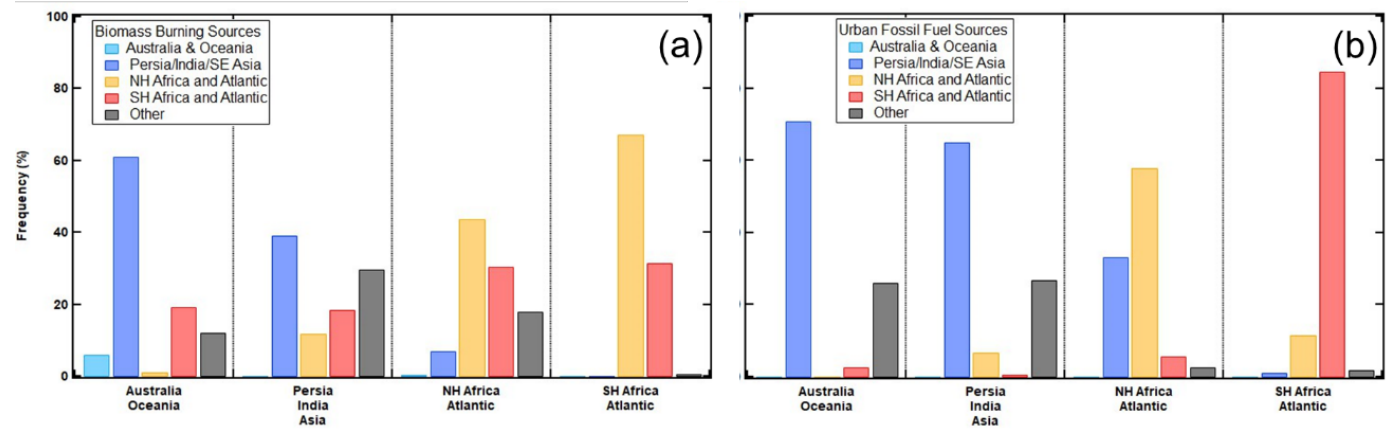

Figure 5. The percentage of $\mathrm{CO}$ anomalies from a) biomass burning and b) urban pollution are shown by the source of the CO (colored bars) within each geographical region.

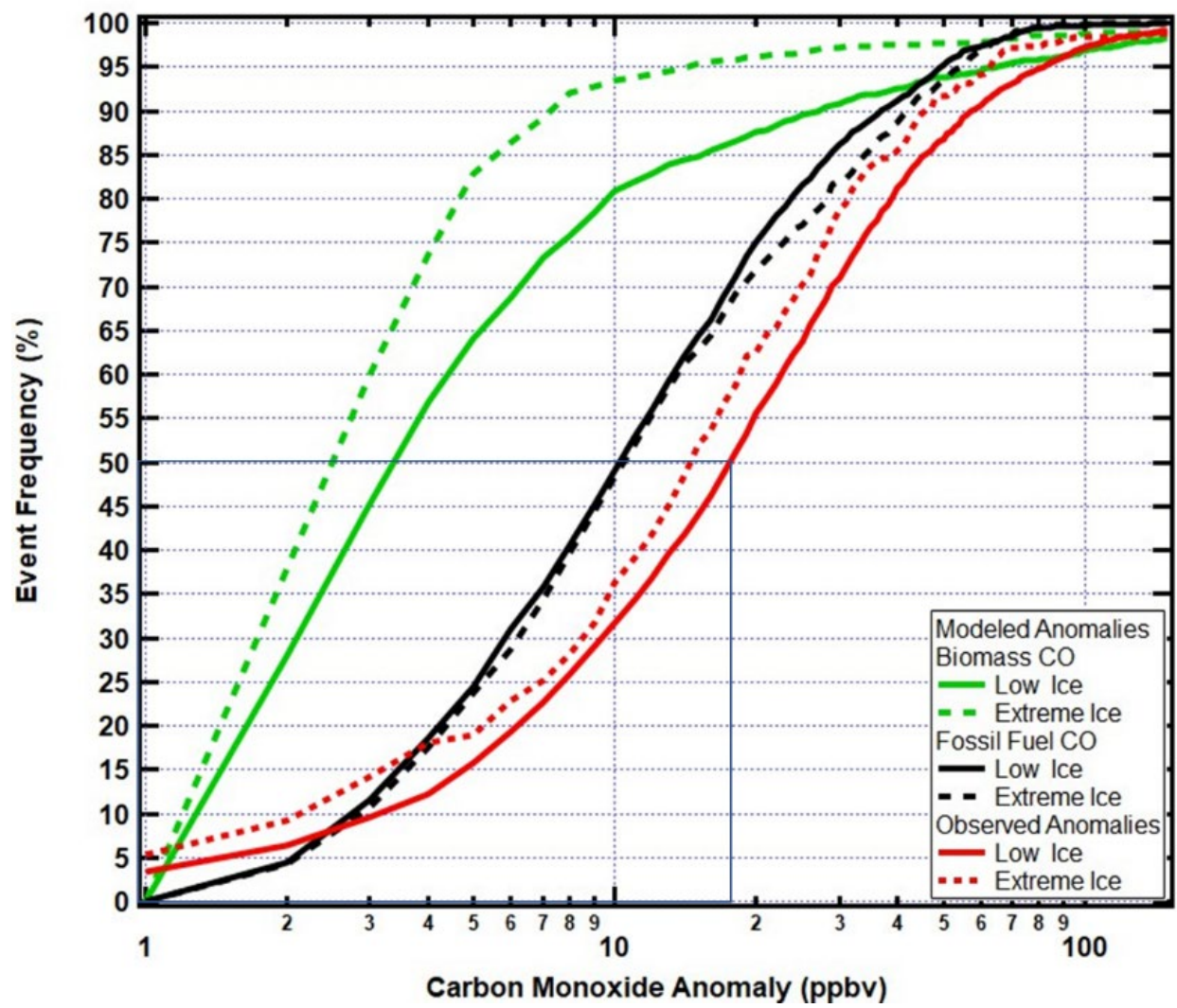

Figure 6. The cumulative frequency distributions of $C O$ anomalies differentiated by source (model-derived biomass burn in green; model-derived-fossil fuel in black; measurement-derived in red). Further separation is made by classify for non-EIE (Low ice, solid curve) and EIE (Extreme ice, dashed curve) 
https://doi.org/10.5194/acp-2021-288

Preprint. Discussion started: 12 May 2021

(c) Author(s) 2021. CC BY 4.0 License.

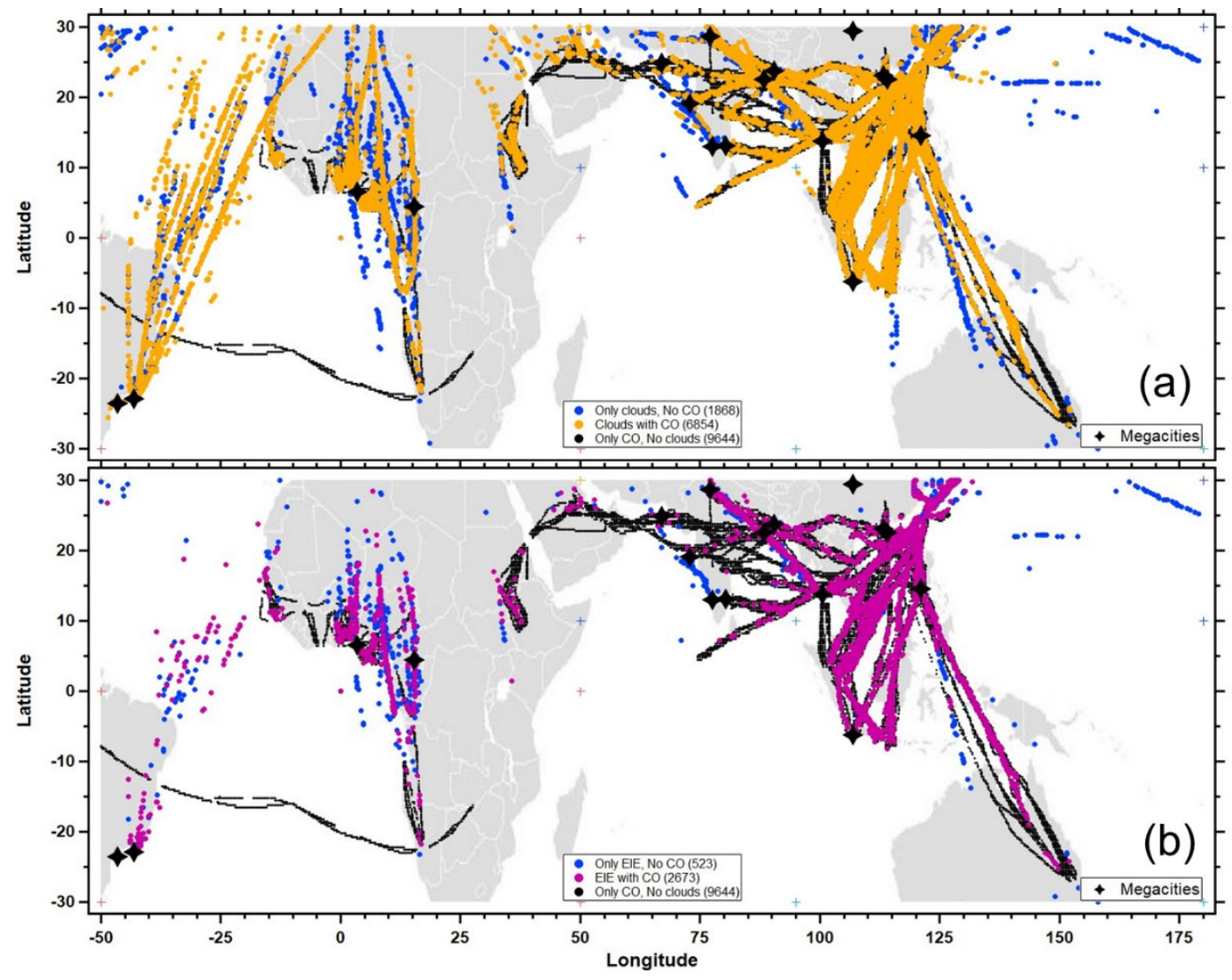

Figure 7. Carbon monoxide (CO) concentration anomalies (color scale) co-located with a) all ice clouds and b) only clouds with Extreme Ice Events (EIE). The back star symbols indicate the location of megacities. 
https://doi.org/10.5194/acp-2021-288

Preprint. Discussion started: 12 May 2021

(c) Author(s) 2021. CC BY 4.0 License.
Atmospheric

Chemistry

and Physics

Discussions
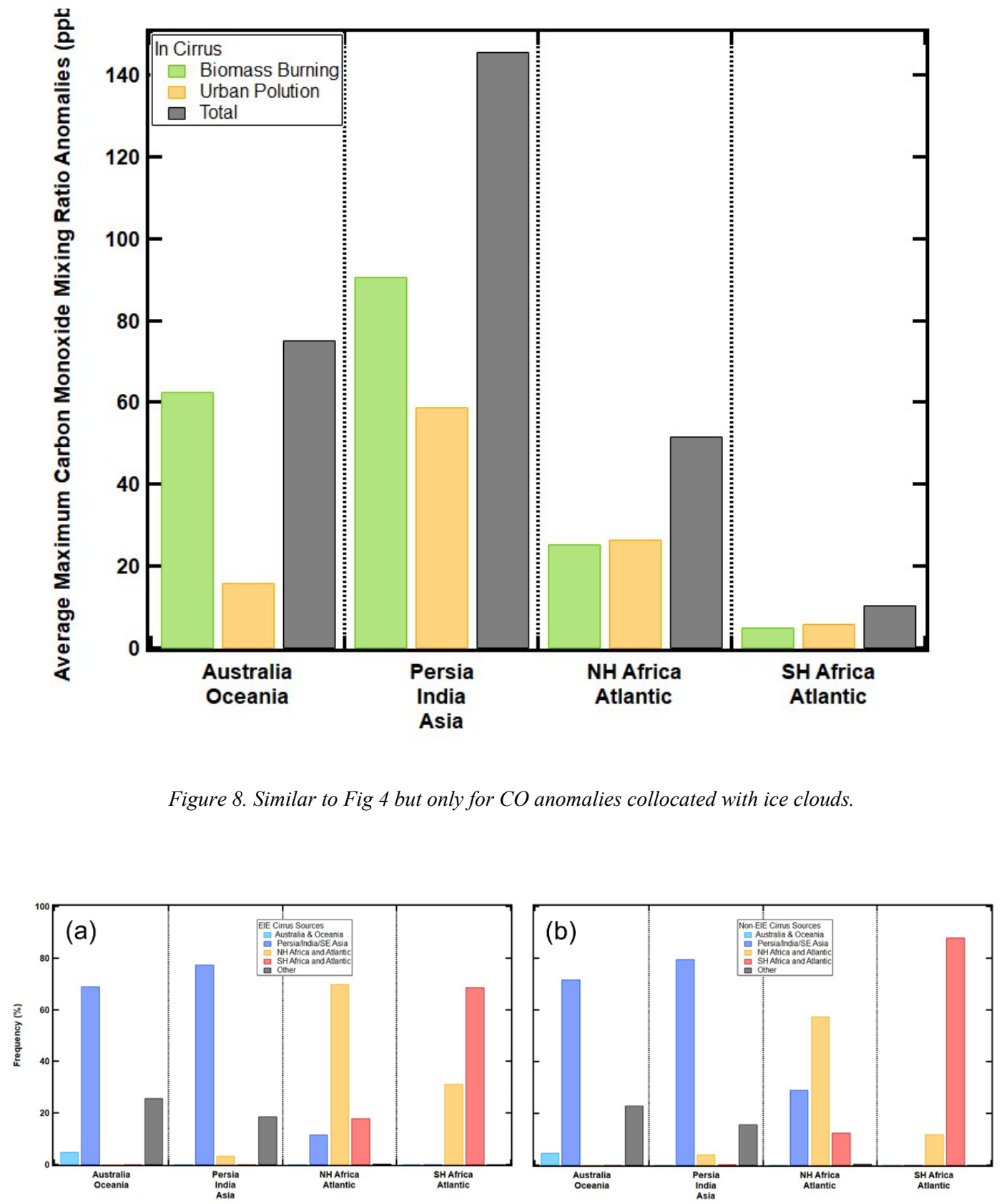

Figure 9. Similar to Fig. 5 but a) the percentage of CO anomalies under EIE ice cloud conditions and b) non-EIE shown by the source region of the CO (colored bars) within each geographical region. 

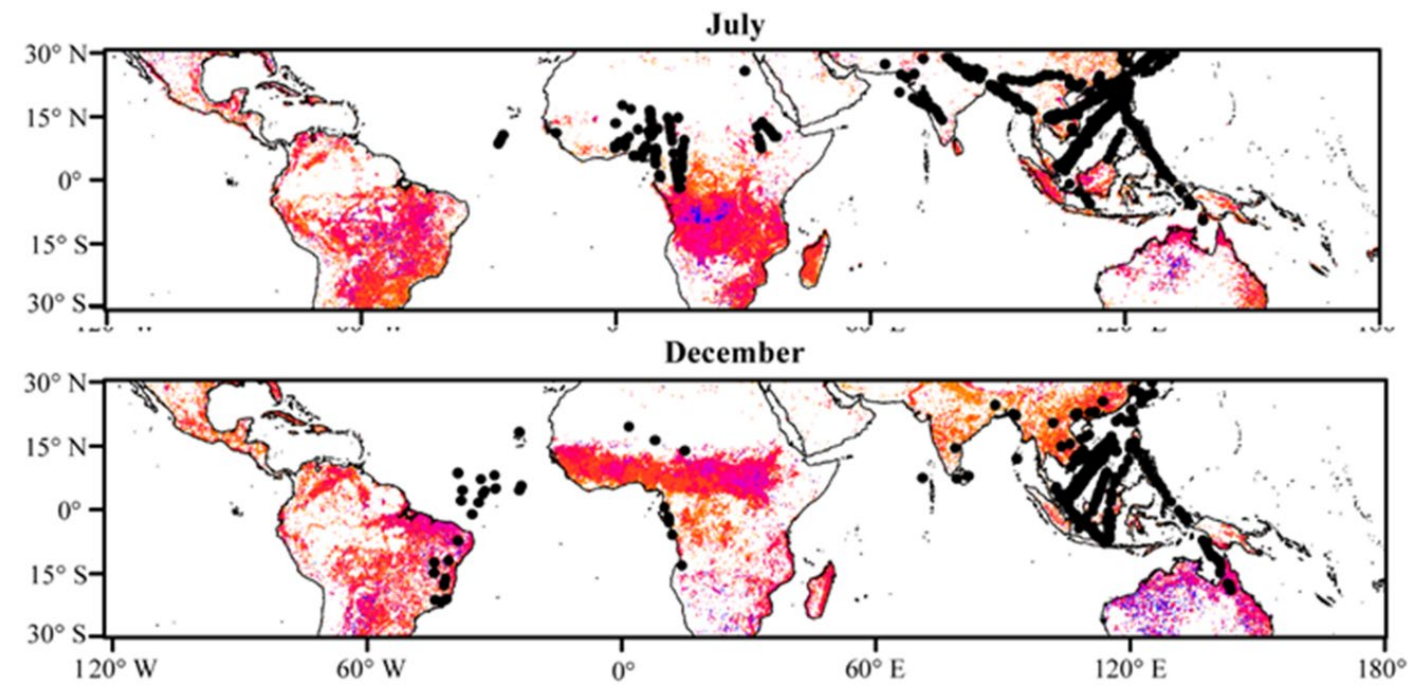

FRP (MW)

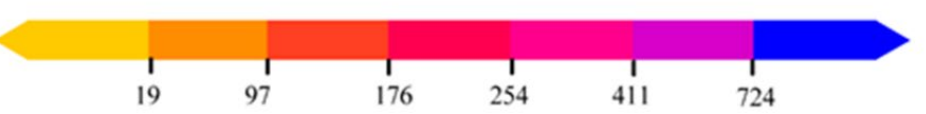

Figure 10. Spatial distribution of the fire radiative power derived from MODIS on the Terra satellite (nadir pass at 1:30pm LT) for July and December (2011-2019). The black markers show the location of EIE observed in each month. 

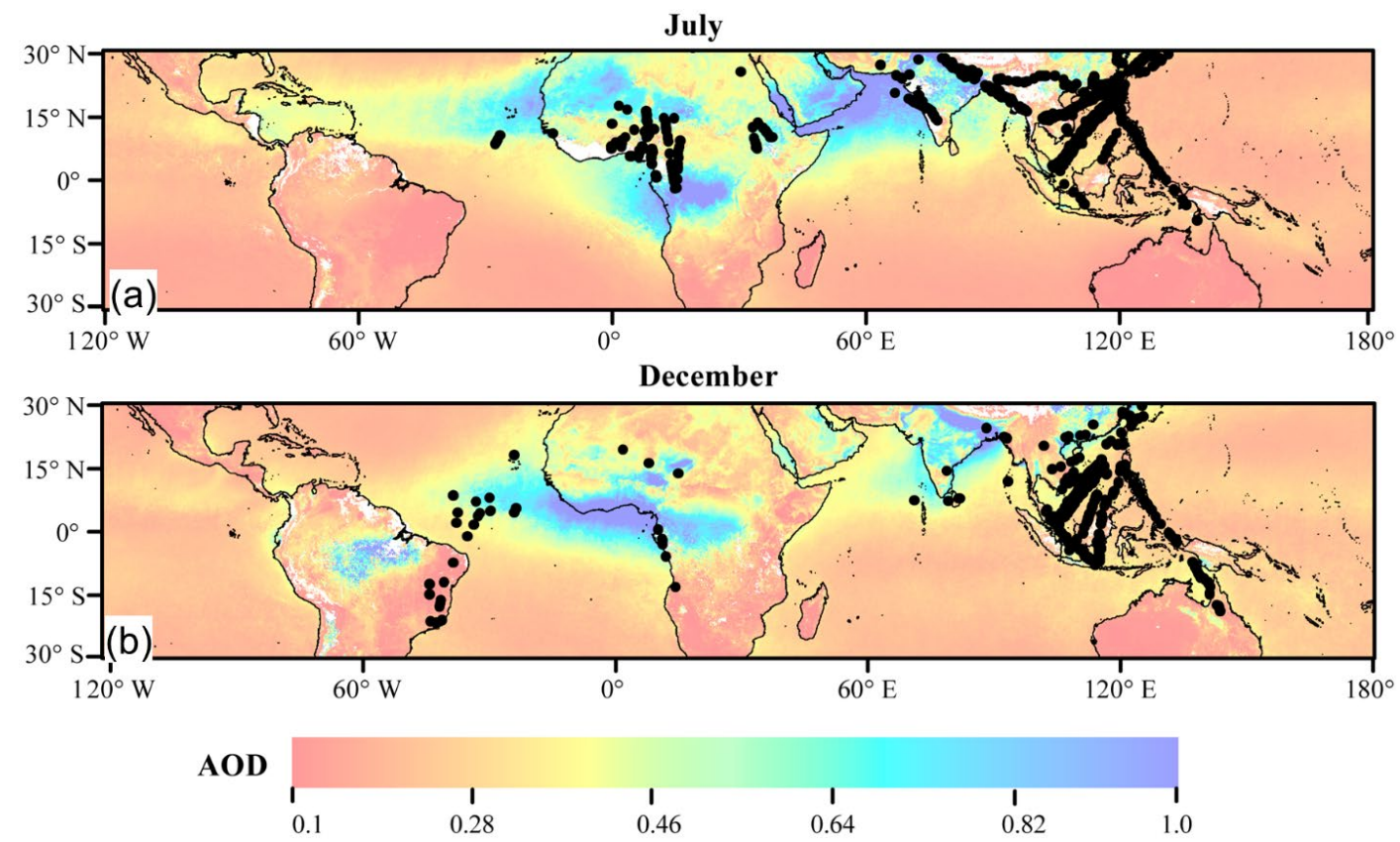

775 Figure 11. Spatial distribution of the aerosol optical depth (AOD) derived from MODIS on the Aqua satellite (nadir pass at 1:30pm LT), 2011-2019 for a) July and b) December. The EIE for July and December are shown as black markers. The AOD has been normalized so that the maximum value is unity. The few white regions correspond to grid points with very high fraction of clouds so that a valid retrieval of $A O D$ is not possible. 
https://doi.org/10.5194/acp-2021-288

Preprint. Discussion started: 12 May 2021

(c) Author(s) 2021. CC BY 4.0 License.
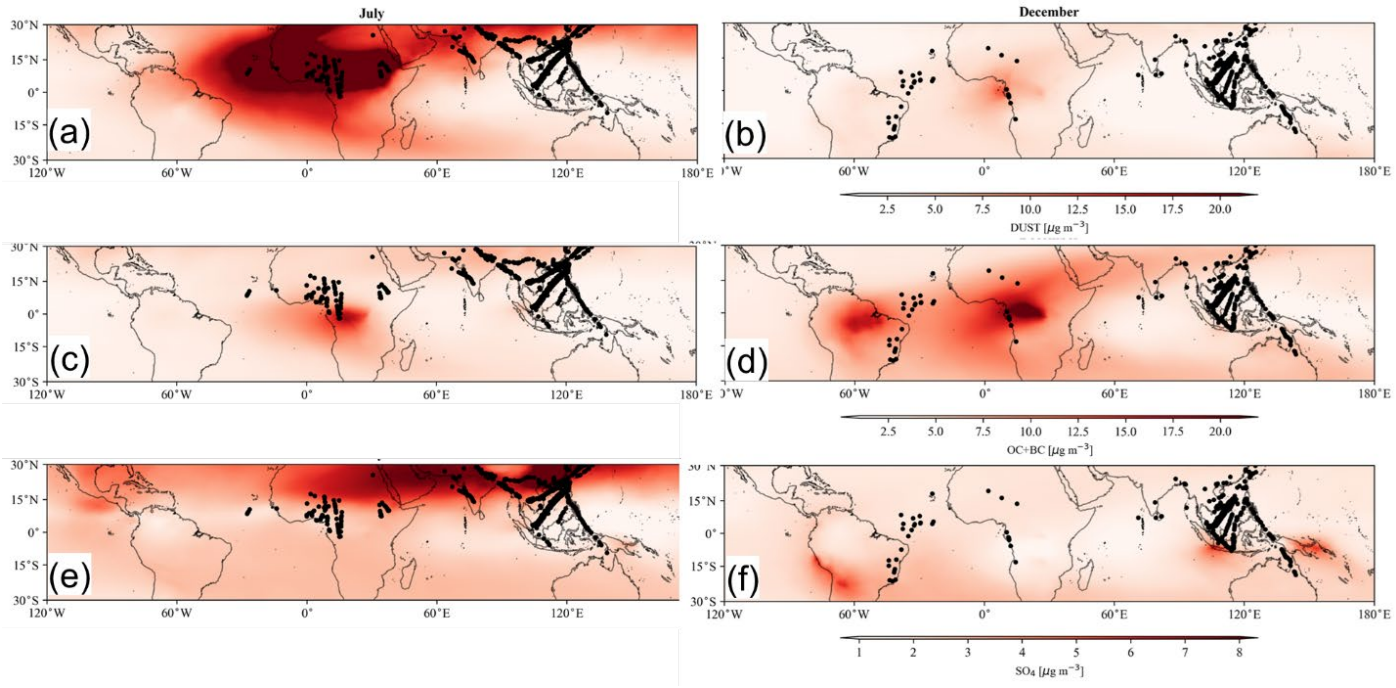

Figure 12. Average particle mass concentrations by aerosol composition, for July (left panels) and December (right panels), derived from MERRA-2 for: $a, b)$ dust, $c, d)$ organic and black carbon $(O C+B C)$ and e,f) sulfate. These are average concentrations between 8 and $12 \mathrm{~km}$ adjusted to standard temperature and pressure. The EIE for July and

December are shown as black markers. 

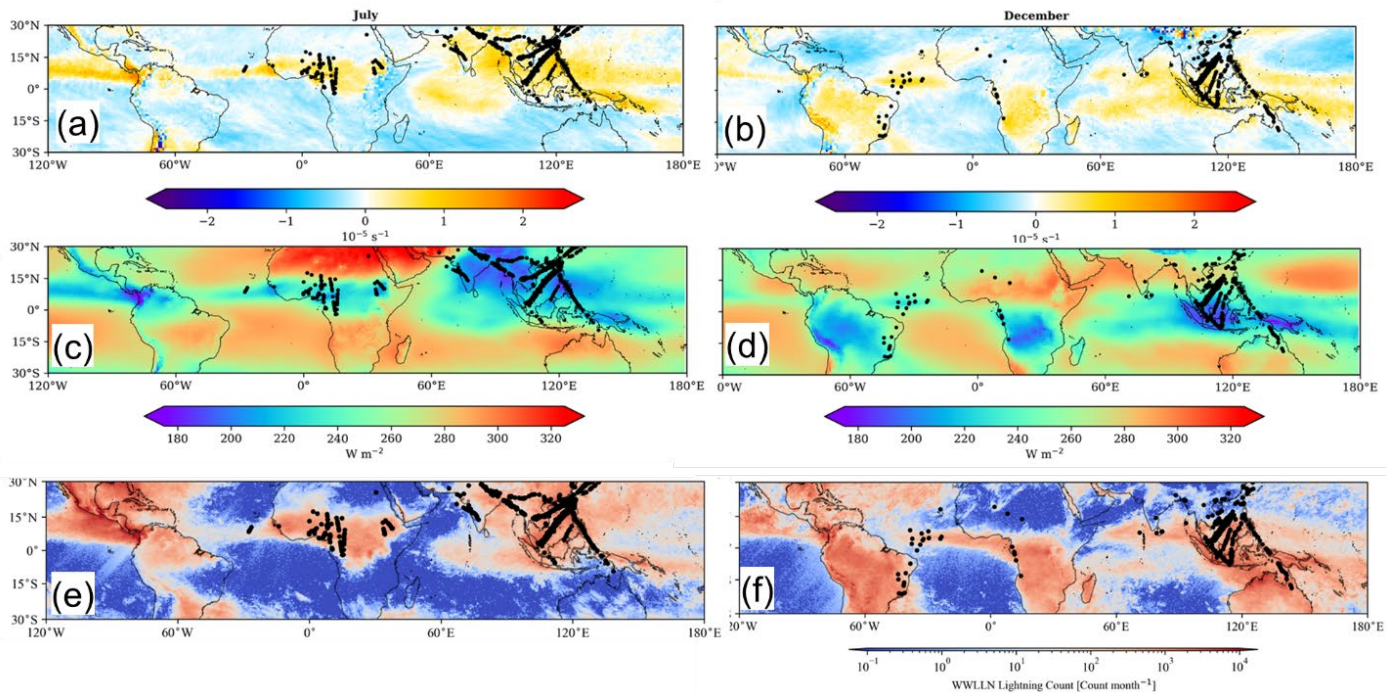

790

Figure 13. Spatial distribution of the monthly average of horizontal wind divergence at $200 \mathrm{hPa}$, determined from ERA5 reanalysis (2011-2019) during a) July and b) December. Spatial distribution of the monthly average of outgoing long wave radiance for c) July and d) December. Spatial distribution of the monthly lightning flash count, derived from the World Wide Lightning Location Network (2011-2018) for e) July and f) December. The EIE for July and December are shown as black markers. 
https://doi.org/10.5194/acp-2021-288

Preprint. Discussion started: 12 May 2021

(c) Author(s) 2021. CC BY 4.0 License.

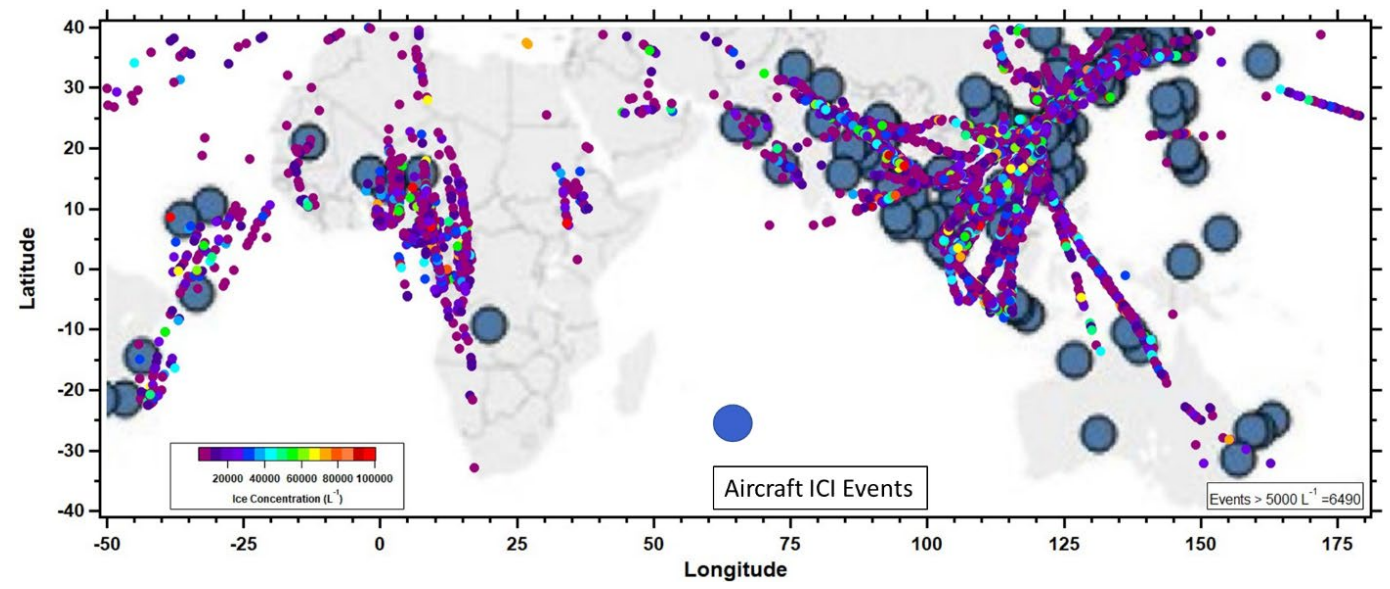

800 Figure 14. EIE, color-coded by concentration, superimposed on the map of ice crystal icing (ICI) events (filled blue circles). The ICI map is reprinted from Bravin and Strapp (2020) with permission from the Society of Automotive Engineers (SAE) International Journal on Advances \& Current Practices in Mobility. 
Table 1

Average [Standard Deviation] Carbon Monoxide Anomalies

\begin{tabular}{|c|c|c|c|c|c|}
\hline \multirow{2}{*}{ Region } & \multicolumn{3}{|c|}{ CO Source } & \multicolumn{2}{c|}{ Season } \\
\cline { 2 - 6 } & $\begin{array}{c}\text { Biomass } \\
\text { Burning }\end{array}$ & $\begin{array}{c}\text { Fossil Fuel } \\
\text { Combustion }\end{array}$ & Both & Dry & Rainy \\
\hline Australia \& & 38 & 11 & 45 & 7 & 15 \\
Oceania & {$[69]$} & {$[13]$} & {$[73]$} & {$[11.5]$} & {$[31.0]$} \\
\hline Persia, India \& & 61 & 46 & 98 & 12.5 & 22.6 \\
Southeast Asia & {$[104]$} & {$[39]$} & {$[117]$} & {$[14.2]$} & {$[27.0]$} \\
\hline Northern Hemisphere & 15 & 20 & 34 & 13.6 & 13.7 \\
Africa \& Atlantic & {$[16]$} & {$[17]$} & {$[28]$} & {$[10.6]$} & {$[11.0]$} \\
\hline Northern Hemisphere & 7 & 5 & 12 & 7.5 & 13.6 \\
Africa \& Atlantic & {$[9]$} & {$[3]$} & {$[11]$} & {$[3.0]$} & {$[10.2]$} \\
\hline
\end{tabular}

Table 2

Average [Standard Deviation] Carbon Monoxide Anomalies

\begin{tabular}{|c|c|c|c|}
\hline \multirow{2}{*}{ Region } & \multicolumn{3}{|c|}{ CO Source } \\
\cline { 2 - 4 } & $\begin{array}{c}\text { Biomass } \\
\text { Burning }\end{array}$ & $\begin{array}{c}\text { Fossil Fuel } \\
\text { Combustion }\end{array}$ & Both \\
\hline Australia \& & 63 & 16 & 75 \\
Oceania & {$[90]$} & {$[15]$} & {$[98]$} \\
\hline Persia, India \& & 91 & 58 & 145 \\
Southeast Asia & {$[128]$} & {$[42]$} & {$[144]$} \\
\hline Northern Hemisphere & 26 & 27 & 52 \\
Africa \& Atlantic & {$[22]$} & {$[19]$} & {$[33]$} \\
\hline Northern Hemisphere & 5 & 6 & 10 \\
Africa \& Atlantic & {$[6]$} & {$[2]$} & {$[7]$} \\
\hline
\end{tabular}

